\title{
Multiple roles for polypyrimidine tract binding (PTB) proteins in trypanosome RNA metabolism
}

\author{
MICHAEL ZEEV STERN, ${ }^{1,3}$ SACHIN KUMAR GUPTA, ${ }^{1,3}$ MALI SALMON-DIVON, ${ }^{1}$ TOMER HAHAM, ${ }^{1}$

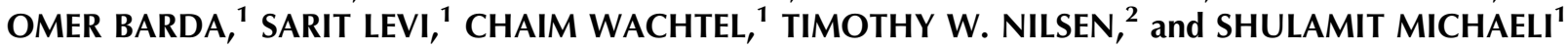 \\ ${ }^{1}$ The Mina and Everard Goodman Faculty of Life Sciences, Bar-llan University, Ramat-Gan 52900, Israel \\ ${ }^{2}$ Center for RNA Molecular Biology, Case Western Reserve University, School of Medicine, Cleveland, Ohio 44106-4973, USA
}

\begin{abstract}
Trypanosomatid genomes encode for numerous proteins containing an RNA recognition motif (RRM), but the function of most of these proteins in mRNA metabolism is currently unknown. Here, we report the function of two such proteins that we have named PTB1 and PTB2, which resemble the mammalian polypyrimidine tract binding proteins (PTB). RNAi silencing of these factors indicates that both are essential for life. PTB1 and PTB2 reside mostly in the nucleus, but are found in the cytoplasm, as well. Microarray analysis performed on PTB1 and PTB2 RNAi silenced cells indicates that each of these factors differentially affects the transcriptome, thus regulating a different subset of mRNAs. PTB1 and PTB2 substrates were categorized bioinformatically, based on the presence of PTB binding sites in their $5^{\prime}$ and $3^{\prime}$ flanking sequences. Both proteins were shown to regulate mRNA stability. Interestingly, PTB proteins are essential for trans-splicing of genes containing C-rich polypyrimidine tracts. PTB1, but not PTB2, also affects cis-splicing. The specificity of binding of PTB1 was established in vivo and in vitro using a model substrate. This study demonstrates for the first time that trans-splicing of only certain substrates requires specific factors such as PTB proteins for their splicing. The trypanosome PTB proteins, like their mammalian homologs, represent multivalent RNA binding proteins that regulate mRNAs from their synthesis to degradation.
\end{abstract}

Keywords: PTB; trans- and cis-splicing; SL RNA; Trypanosoma brucei

\section{INTRODUCTION}

Trypanosomatids are protozoan parasites that diverged early in the eukaryotic lineage, long before yeast (Sogin et al. 1986). The regulation of their gene expression is nonconventional compared with other eukaryotes, as protein-coding genes are arrayed in long polycistronic transcription units, and the genes lack promoters. mRNAs are formed by the concerted action of trans-splicing and polyadenylation (Agabian 1990; Liang et al. 2003). Transsplicing involves the addition of a common exon, the spliced leader (SL) from a small RNA, the SL RNA to all mRNAs. Trans-splicing resembles cis-splicing, but instead of a lariat intermediate a Y structure is formed during the first step of the reaction. Trans-splicing, like cis-splicing, requires the action of $\mathrm{U} 2, \mathrm{U} 4, \mathrm{U} 5$, and $\mathrm{U} 6$ snRNPs, but not

\footnotetext{
${ }^{3}$ These authors contributed equally to this work.

Reprint requests to: Shulamit Michaeli, The Mina and Everard Goodman Faculty of Life Sciences, Bar-Ilan University, Ramat-Gan 52900, Israel, e-mail: michaes@mail.biu.ac.il; fax: 972-3-5318124.

Article published online ahead of print. Article and publication date are at http://www.rnajournal.org/cgi/doi/10.1261/rna.1230209.
}

U1 snRNP (Liang et al. 2003). Trans-splicing takes place in a $45 \mathrm{~S}$ spliceosomal complex carrying the splicing intermediates and splicing factors (Liang et al. 2006). Cissplicing also occurs in trypanosomes (Mair et al. 2000), but so far, only three substrates that undergo this reaction have been identified (Ivens et al. 2005). Very little is known about splicing regulation in these organisms. While factors such as SR proteins and hnRNP protein homologs were identified in the genome, their role in splicing regulation has not yet been established (Liang et al. 2003; De Gaudenzi et al. 2005). Most mRNAs tested so far are regulated primarily at the level of mRNA degradation via signals located in the $3^{\prime}$ untranslated region, which affect both mRNA stability and translatability (Clayton 2002; De Gaudenzi et al. 2005; Clayton and Shapira 2007).

Post-transcriptional processing is regulated by RNA binding proteins that contain the RNA recognition motif (RRM domain). This protein domain is necessary and sufficient for binding RNA molecules with a wide range of specificities and affinities (Maris et al. 2005). Recently, it was suggested that the RRM domain can also regulate protein-protein interactions (Maris et al. 2005). The Trypanosoma brucei genome contains 80 proteins carrying 
RRM domains, compared with 497 proteins present in humans (De Gaudenzi et al. 2005; Maris et al. 2005).

One of the most interesting RRM-containing proteins in mammals is the polypyrimidine tract binding protein (PTB), also known as hnRNP I, which acts at multiple steps during mRNA biogenesis. PTB has been implicated in the repression of a large number of alternative splicing events (Wagner and Garcia-Blanco 2001). PTB recognizes short motifs, such as UCUU and UCUC, located within a polypyrimidine-rich context (Ashiya and Grabowski 1997; Chan and Black 1997; Perez et al. 1997; Gooding et al. 1998; Carstens et al. 2000). PTB binds to the polypyrimidine tract near the $3^{\prime}$ splice site, but also binds to exonic sequences and to introns downstream of regulated exons (Cote et al. 2001; Le Guiner et al. 2001; Shen et al. 2004; Izquierdo et al. 2005). The mechanism by which PTB exerts its repression on splicing is complex. Several models were suggested that depend on the location of PTB binding relative either to the exon, intron, or the two introns flanking the regulated exon. It was proposed that PTB directly competes with U2AF65 and thereby inhibits the assembly of U2 snRNP at the branch point (Mulligan et al. 1992; Lin and Patton 1995; Singh et al. 1995; Chou et al. 2000; Amir-Ahmady et al. 2005). Recent data suggest that the mechanism of repression might be more complex, involving specific interference with the cross-talk between U1 snRNP and U2AF65, which is responsible for intron or exon definition (Spellman and Smith 2006).

PTB was shown not only to regulate splicing but also to affect polyadenylation by competing with CstF64 binding to the downstream $U$ or $U / G$ region of the poly(A) site. It was shown that PTB can repress both splicing and polyadenylation (Le Sommer et al. 2005).

PTB is mostly found in the nucleus, although it was demonstrated that the protein shuttles between the nucleus and the cytoplasm through a mechanism that is distinct from RNA export (Kamath et al. 2001). In the cytoplasm, PTB has been shown to stabilize mammalian mRNAs by binding to the 3' UTR (Soderberg et al. 2002; Kosinski et al. 2003; Tillmar and Welsh 2004). In addition, PTB has been shown to regulate mRNA localization (Cote et al. 1999) and internal ribosome entry site (IRES)-mediated translation during apoptosis (Bushell et al. 2006).

Of special interest are two trypanosome RNA binding proteins that resemble the mammalian $\mathrm{PTB}$, named DRBD3 and DRBD4 (PTB1 and PTB2 in this study) (De Gaudenzi et al. 2005). It was proposed that these proteins may jointly perform the function of mammalian PTB. Recently, it was suggested that DRBD4 in Trypanosoma cruzi functions in masking trans-splicing/polyadenylation signals, leading to the production of dicistronic mRNAs, since DRBD4 was found to bind the dicistronic mRNAs present in the cytoplasm (Jager et al. 2007).

In this study, we investigated the role of two PTBs, PTB1 and PTB2 (DRBD3 and DRBD4, respectively), in mRNA processing and stability in T. brucei. RNAi silencing of each of these factors decreased the level of SL RNA and the level of the trans-splicing Y structure intermediate, accordingly. These results suggest that neither of these proteins is a general splicing factor, since their depletion does not affect the splicing of all mRNAs, in contrast to the major splicing defect observed for the depletion of splicing factors such as PRP31 and PRP43, Sm, or Lsm proteins (Mandelboim et al. 2003; Liu et al. 2004; Liang et al. 2006). Microarray analysis of PTB1 and PTB2 silenced cells demonstrate different effects on the transcriptome, suggesting that these two proteins bind to different subsets of mRNAs, and most probably do not function jointly. Both PTB1 and PTB2 were shown to either stabilize or destabilize different subsets of mRNAs. The trans-splicing of a subset of genes was shown to be dependent on PTB1 or PTB2. This study suggests that the trypanosome PTB proteins are multifunctional RNA binding proteins that function in both splicing and in regulating mRNA stability. This is the first study to demonstrate a differential need of splicing factors for transsplicing of trypanosome mRNAs.

\section{RESULTS}

\section{The homology of PTB1 and PTB2 to the mammalian PTB}

Inspection of the T. brucei genome revealed several proteins that could potentially participate in the regulation of transsplicing (Liang et al. 2003). Two previously identified proteins, DRBD3 and DRBD4, have similarity to the mammalian PTB (De Gaudenzi et al. 2005). Based on this homology, we renamed DRBD3 as PTB1; this protein is annotated in GeneDB as Tb09.211.0560. We renamed DRBD4 as PTB2, which is annotated as Tb11.01.5690. To further demonstrate that these proteins are in fact $T$. brucei PTB homologs, we compared the structure of T. brucei proteins to the human PTB proteins (NP_002810.1 and nPTB NP_067013.1). A schematic comparison of their putative domain structure is given in Figure 1A, and the identity and similarity of the RRM domains of the human proteins to either PTB1 or PTB2 are shown in Figure 1B. The positions of the RRM domains in the proteins are indicated in the boxes, and arrows link the residues that are related in each domain. The data presented in Figure 1 suggest that the RRM 1 and RRM 2 of T. brucei PTB1 are mostly related to corresponding RRMs of human proteins PTB and nPTB; RRM1, RRM 2, and RRM 3 of T brucei PTB2 resemble most closely RRM1, RRM3, and RRM4 of human proteins PTB and nPTB. T. brucei PTB2 does not contain the human RRM2 homolog. There is a vestigial RRM domain at positions $98-163$ of the protein that most closely resembles RRM 2 of the human protein. In fact, the domain database (based on the programs SMART, FPAM, PROSITE, and INTERPROSCAN) was not able to detect an 
A

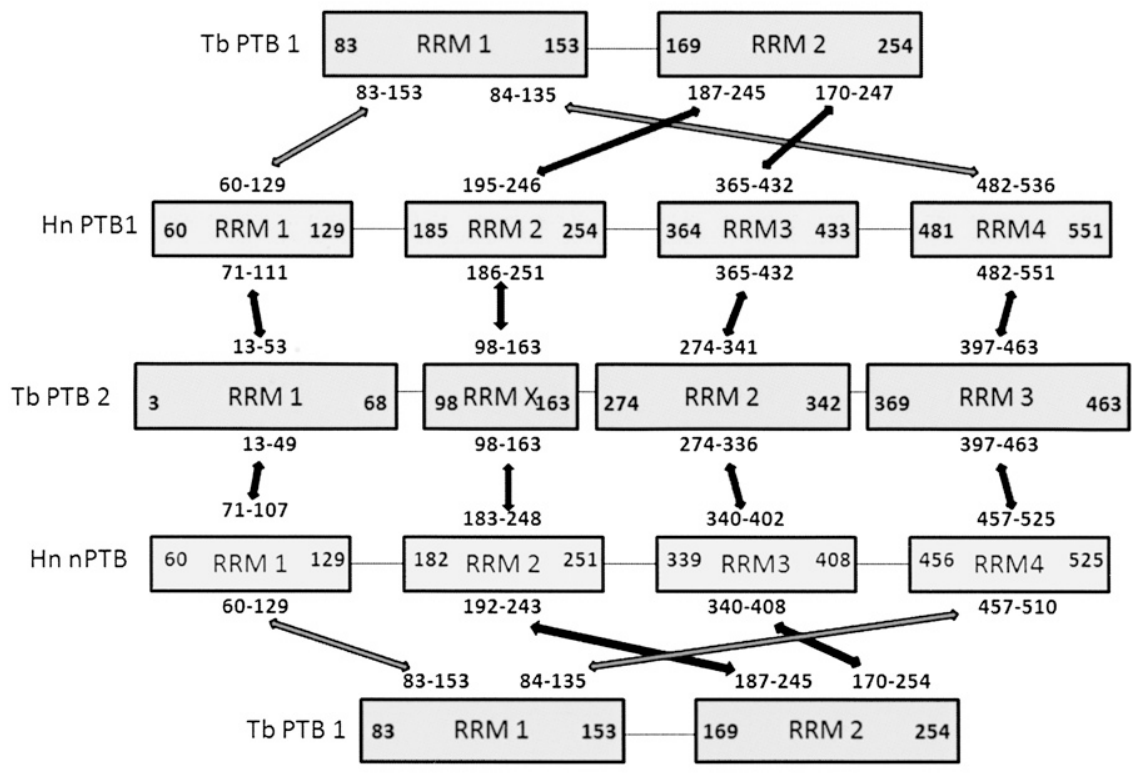

B

\begin{tabular}{|c|c|c|c|c|c|c|c|c|}
\hline \multirow[b]{2}{*}{ Tb PTB 1} & \multicolumn{4}{|c|}{ HUMAN PTB ( PTB1) } & \multicolumn{4}{|c|}{ HUMAN nPTB (PTB 2) } \\
\hline & RRM 1 & RRM 2 & RRM 3 & RRM 4 & RRM 1 & RRM 2 & RRM 3 & RRM 4 \\
\hline RRM 1 & \begin{tabular}{|l|} 
Identity 29.6 \\
Similanty 62
\end{tabular} & & & \begin{tabular}{|l|} 
Identity 31.6 \\
Similarity 56.1
\end{tabular} & \begin{tabular}{|l} 
Identty 28.2 \\
Similanty 59.2
\end{tabular} & & & \begin{tabular}{|l} 
Identity 29.6 \\
Similanty 53.7
\end{tabular} \\
\hline RRM 2 & & \begin{tabular}{|l} 
Identity 33.9 \\
Similarity 55.9
\end{tabular} & \begin{tabular}{|l} 
Identity 28.6 \\
Similarity 45.2
\end{tabular} & & & \begin{tabular}{|l} 
Identity 35.6 \\
Similarty 54.2
\end{tabular} & \begin{tabular}{|l} 
Identity 27.1 \\
Similanity 44.7
\end{tabular} & \\
\hline Tb PTB 2 & RRM 1 & RRM 2 & RRM 3 & RRM 4 & RRM 1 & RRM 2 & RRM 3 & RRM 4 \\
\hline RRM 1 & \begin{tabular}{|l|} 
Identity 24.4 \\
Similanty 48.8
\end{tabular} & & & & \begin{tabular}{|l} 
Identity 24.3 \\
Similanity 48.6
\end{tabular} & & & \\
\hline RRM X & & \begin{tabular}{|l} 
Identily 30.3 \\
Similarity 47
\end{tabular} & & & & \begin{tabular}{|l} 
Identity 27.3 \\
Similanty 47
\end{tabular} & & \\
\hline RRM 2 & & & \begin{tabular}{|l|} 
Identity 32.4 \\
Similarity 55.9
\end{tabular} & & & & $\begin{array}{l}\text { Identity } 302 \\
\text { Similarity } 54\end{array}$ & \\
\hline RRM 3 & & & & \begin{tabular}{|l|} 
Identity 34.3 \\
Similarity 64.3
\end{tabular} & & & & \begin{tabular}{|l|} 
Identity 29 \\
Similanity 59.4
\end{tabular} \\
\hline
\end{tabular}

FIGURE 1. Schematic representation of the comparison between the human PTB (PTB1 and $\mathrm{nPTB}$ ) and Tb PTB (PTB1 and PTB2). The amino acid sequence of the mammalian proteins PTB1 (NP_002810.1) and nPTB (NP_067013.1) were compared to trypanosome PTB1 (Tb09.211.0560) and PTB2 (Tb11.01.5690) using the program pBLAST (Altschul et al. 1997) and Psi BLAST (Altschul et al. 1997). To examine the relatedness of each of the RRM domains of the mammalian proteins to the corresponding trypanosome sequences, the programs SMART, FPAM, PROSITE, and INTERPROSCAN were used. The position of the mammalian RRM domains was based on data from Wagner and Garcia-Blanco (2001). (A) Comparison between the RRM domains. Each RRM domain is boxed. The amino acids that are related between the PTB proteins are connected with arrows, and the exact positions are given outside the box. $(B)$ The relatedness (identity and similarity) between the RRM domains are shown between the PTB proteins specified in $A$.

RRM2 homologous domain. Only when we used the program SMART, with the sequence of amino acids 98163, was this domain identified as an RRM domain, although with a relatively poor score. We termed this divergent domain RRM X.

We next searched the entire genome as well as the list of all RRM-containing proteins in T. brucei (De Gaudenzi et al. 2005) with the human PTB isoforms (indicated in Fig. 1). The two proteins that appeared on the top of the list were PTB2 $\left(7 \mathrm{e}^{-1019}\right)$ and PTB1 $\left(3 \mathrm{e}^{-016}\right)$.

\section{Silencing by RNAi of PTB1 and PTB2 demonstrates that both factors are essential for growth}

To examine the role of PTB proteins in trypanosome RNA metabolism, and particularly to determine if these factors participate in trans- and cis-splicing, the expression of these genes was silenced by RNAi. PTB1 and PTB2 were amplified from the genome, and stem-loop constructs were designed. The constructs were composed of a 479-basepair (bp) stem for PTB1 and a 443-bp stem for PTB2, and both carried a stuffer derived from Pex sequences (Wang et al. 2000). These constructs were cloned downstream of a tetracyclineregulated EP promoter and used to transfect T. brucei (29-13) expressing the tetracycline repressor and T7 polymerase (Wang et al. 2000). Cloned cells expressing the constructs were selected on phleomycin. Figure 2A shows the growth of the PTB1 and PTB2 silenced cells, demonstrating marked reduction in cell growth upon silencing of each of these factors. Although the growth of both PTB1 and PTB2 silenced cells was inhibited, PTB2 silenced cells were more severely affected. The difference may result from the effect on the processing or stability of different subset of mRNAs by these two factors (see below). The reduction in the corresponding mRNAs and proteins in the silenced cells is presented in Figure 2, B and C. The results indicate induction of dsRNA production and an $80 \%-100 \%$ reduction in the level of the corresponding mRNAs.

Antibodies were raised against PTB1 and PTB2, as described in Materials and Methods, and used to examine the reduction in the level of proteins upon silencing. The specificity of the antibodies was examined using T. brucei whole cell extracts, and the results in Figure 2C (left panel) show that each antibody recognizes only a single polypeptide. Upon silencing, complete elimination of the corresponding protein was observed (Fig. 2C, right 
panel). These results suggest that the silencing of PTB1 and PTB2 was very efficient and that these factors are essential for life.
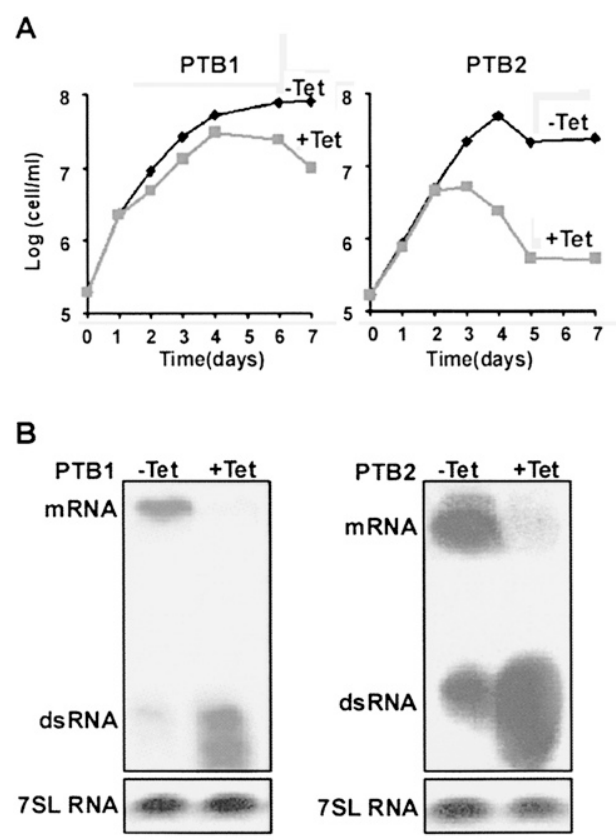

C

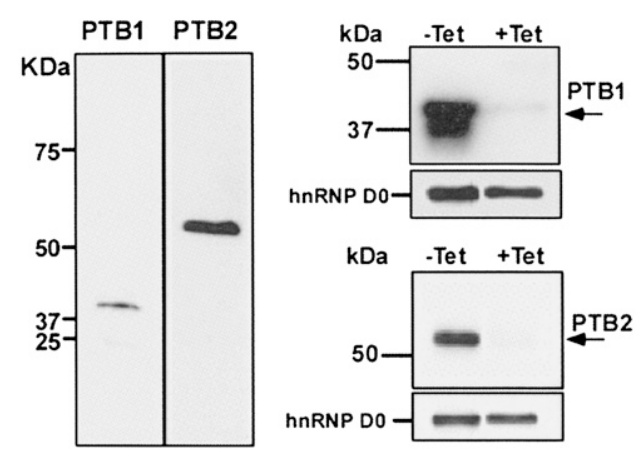

FIGURE 2. (A) PTB1 and PTB2 are essential genes. The growth of uninduced cells $(-\mathrm{Tet})$ was compared with cells induced for dsRNA production (+Tet). The number of cells in the uninduced cultures is designated by black diamonds; the number in the induced cultures, by gray squares. $(B)$ Northern analysis of PTB1 and PTB2 upon RNAi silencing. RNA was prepared from uninduced cells and cells after $3 \mathrm{~d}$ of induction. Total RNA $(20 \mu \mathrm{g})$ was separated on a $1.2 \%$ agarose-2.2 M formaldehyde gel. The RNA was blotted and hybridized with a randomly labeled probe specific for the two genes. The level of 7SL RNA (control for equal loading) was detected by hybridization with the anti-sense 7SL RNA oligonucleotide. The identity of the transcripts is indicated. $(C)$ Western analysis of the PTB proteins $(l e f t)$. Whole cell extract $(30 \mu \mathrm{g})$ was separated on $12 \%$ SDS-polyacrylamide and subjected to Western analysis using antiPTB antibodies (diluted 1:10,000). Molecular mass markers are indicated. Western analysis of the level of PTB proteins upon silencing (right). Total protein extracts from $2 \times 10^{8}$ cells from uninduced and silenced cells $3 \mathrm{~d}$ after induction were separated on 12\% SDSpolyacrylamide gels and subjected to Western analysis using antiPTB1 and anti-PTB2 antibodies (diluted 1:10,000). The level of hnRNP D0 was used as a control for equal loading.

\section{Cellular localization and biochemical fractionation of PTB1 and PTB2}

The localization of PTB proteins was determined by fusing the PTB1 to GFP, or by immunofluorescence, using antibodies to PTB2. The results (Fig. 3A) show images of the entire parasite (long exposure) and short exposure of the nucleus (left corner). The data suggest that both proteins are localized mainly in the nucleus in "speckles," but faint staining was also observed in the cytoplasm.

We next examined the distribution of the factors by fractionating extracts derived from wild-type $T$. brucei at the procyclic stage or extracts from cells carrying a BB2tagged PRP31 protein expressed from its authentic site (Liang et al. 2006). Extracts were prepared under low-salt conditions $(50 \mathrm{mM} \mathrm{KCl})$, and fractionated on a Superdex S-200 FPLC column. The peak fractions of these factors were different (Fig. 3B); PTB1 was found mostly in fractions 22-28, whereas PTB2 was found in fractions 2426. Because of their differential distribution, these factors most probably do not interact with each other. To verify that this is indeed the case, antibodies to each of these proteins were used in immunoprecipitation experiments. The results in Figure $3 \mathrm{C}$ demonstrate that antibodies to PTB1 immunoprecipitated PTB1 but not PTB2, while antibodies to PTB2 precipitated PTB2 but not PTB1. Interestingly, $\mathrm{PTB} 1$ and $\mathrm{PTB} 2$ also do not fractionate together with several of the general splicing factors such as PRP31 or U2AF65. Nevertheless, the size of the complexes carrying PTB1 or PTB2 are in the $66-200-\mathrm{kDa}$ range, suggesting that these factors are likely associated with other splicing or protein factors. Nevertheless, the complexes formed with PTB1 and with PTB2 are significantly smaller than those associated with PRP31 and U2AF65.

\section{PTB1 and PTB2 are not basal splicing factors though their silencing affects the steady-state level of SL RNA and its nascent transcription}

We have previously demonstrated that silencing of basal splicing factors that affect the trans-splicing of all mRNAs results in the elevation of SL RNA levels, since it is not utilized in splicing and therefore accumulates in the cell (Mandelboim et al. 2003; Liu et al. 2004; Liang et al. 2006; Tkacz et al. 2007). To examine whether the PTB1 and PTB2 proteins are basal splicing factors, the effect on the steadystate level of SL RNA was examined by primer extension following PTB silencing. The results presented in Figure 4A suggest that silencing of both factors reduced the steadystate level of SL RNA by $30 \%$ and $60 \%$ in PTB1 and PTB2 silenced cells, respectively. No effect on capping of the SL RNA was observed, since the staggered stops on the cap-4 nucleotides were the same in uninduced cells and in PTB1 or PTB2 depleted cells. To examine if trans-splicing is affected to the same degree as the reduction of SL RNA or more drastically, the level of the Y structure intermediate 

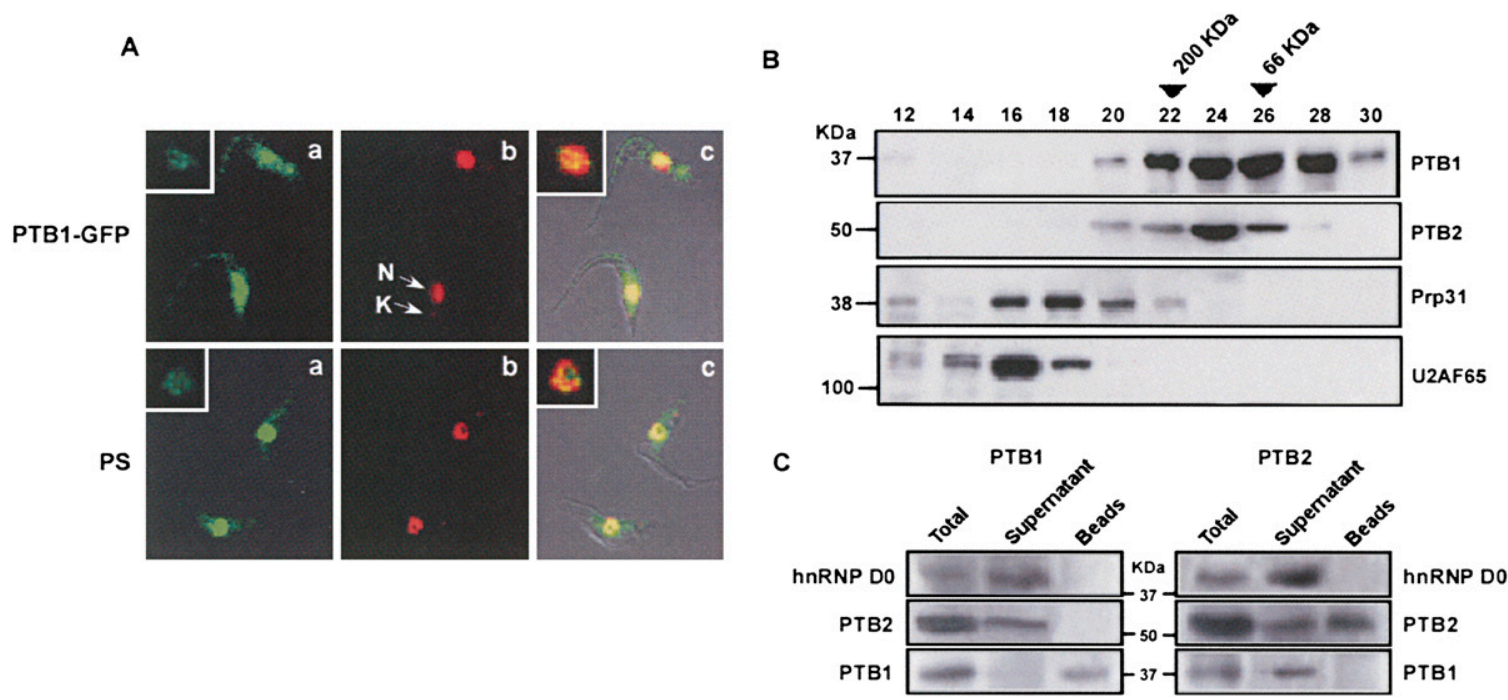

FIGURE 3. (A) Localization of PTB1 and PTB2 in the cell. (Upper panel) Imaging of cells expressing the GFP-PTB1 construct. Cells were fixed in $4 \%$ formaldehyde; (panel $a$ ) fluorescence of PTB1-GFP; (panel $b$ ) nuclei stained with DAPI; $(c)$ DIC merge of panels $a$ and $b$. The images were obtained following long exposure. Enlargement of the nuclear area is framed and was obtained using shorter exposure. (Lower panel) Immunofluorescence of PTB2. Cells were fixed with $2 \%$ paraformaldehyde for 25 min, incubated with antibodies as described in Materials and Methods, and detected by a FITC-conjugated secondary antibody. (Panel $a$ ) Fluorescence of the PTB2 protein; (panel $b$ ) nuclei stained with DAPI; (panel $c$ ) DIC merge of panels $a$ and $b$. The images were obtained following long exposure. Enlargement of the nuclear area is framed and was obtained using shorter exposure. (B) Fractionation of extracts by FPLC to determine the size of complexes associated with PTB proteins. Whole cell extracts were prepared from parental cells or from cells expressing the BB2-tagged Prp31 protein (Liang et al. 2006). Extract preparation and column chromatography are described in Materials and Methods. Proteins were subjected to Western analysis using the relevant antibodies (antiBB2, anti PTB [this study], anti-U2AF65 [kindly provided by Dr. Mariano Levin, Institute for Genetic Engineering and Molecular Biology (INGEBI) and National Council of Science and Technology Research (CONICET)]). The identity of the proteins examined is indicated. The elution positions of the marker proteins, BSA $(66 \mathrm{kDa})$ and $\beta$-amylase $(200 \mathrm{kDa})$, are indicated. $(C)$ Coimmunoprecipitation of PTB proteins. Extract was prepared from $5 \times 10^{9}$ cells, and immunoprecipitation was performed with the antibodies as described in Materials and Methods. The samples were subjected to Western analysis using PTB1 and PTB2 antibodies. Proteins immunoprecipitated with PTB1 were probed with anti-PTB2 and vice versa. Total cell extract and supernatant (5\%) were analyzed alongside whole beads.

was examined using an oligonucleotide complementary to the intron portion of the SL RNA. If trans-splicing is affected at the first step of splicing the level of Y structure is decreased, but if the reaction is affected in the second step the $\mathrm{Y}$ structure accumulates. The results, shown in Figure $4 \mathrm{~B}$, suggest that the reduction in the levels of the $\mathrm{Y}$ structure intermediate $(39 \%$ and $58 \%$, for PTB1 and PTB2, respectively) reflects the reduction in the level of steady-state SL RNA, suggesting that neither PTB1 nor PTB2 affects the trans-splicing of all mRNAs; the reduction in the level of the $\mathrm{Y}$ structure correlates well with the reduction in the level of SL RNA in the silenced cells. Experiments measuring the extent of reduction in SL RNA and the $\mathrm{Y}$ structure intermediate were repeated three times, and the results of these experiments are presented in Figure 4C. At this point, we cannot exclude the possibility that these factors might affect the trans-splicing of only a subset of mRNAs, but the data suggest that neither PTB1 nor PTB2 is a general splicing factor that affects the level of the Y structure intermediate. The defects due to PTB2 silencing are more severe than those observed for PTB1. These differences cannot be attributed to different degrees of silencing, since in both cases silencing resulted in complete elimination of the proteins.
We next examined whether the reduction in the level of SL RNA during silencing results from transcription shutoff of the SL RNA. To this end, a permeable cell system was used (Tschudi and Ullu 1990; Ullu and Tschudi 1990). SL RNA is the major radiolabeled transcript in this system. The results in Figure 5 indicate $54 \%$ and $79 \%$ reductions in the level of newly transcribed SL RNA as a result of PTB1 and PTB2 silencing, respectively.

The effect of PTB proteins on the level of SL RNA can result either from a direct effect or an indirect effect. For instance, PTB proteins can interact with the promoter or with the SL RNA transcription complex. PTB proteins may also bind to the nascent SL RNA before its assembly with the Sm proteins and thus affect the stability of the nascent SL RNA. Alternatively, the effect on SL RNA transcription might be an indirect effect and one of the proteins that are essential for SL RNA transcription may be encoded by a short-lived RNA whose level is regulated (reduced) in PTB silenced cells.

To detect possible direct binding of PTB to the SL RNA promoter, a ChiP assay was performed using antibodies to the PTB proteins. The results (data not shown) suggest that PTB does not directly associate with the DNA of the SL 
A
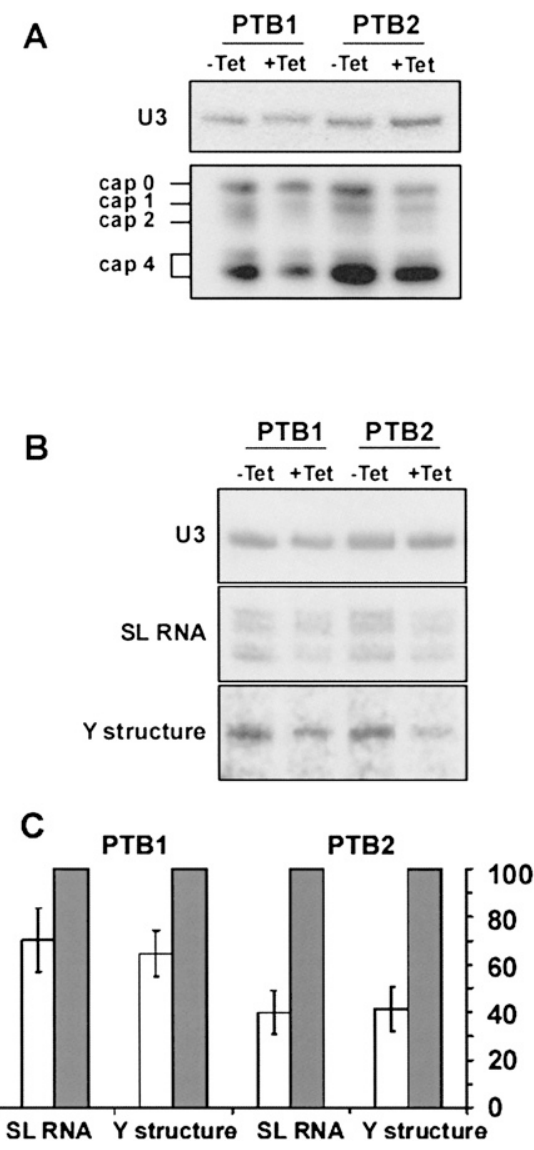

FIGURE 4. The levels of SL RNA and Y structure intermediate upon PTB1 and PTB2 silencing. (A) The level of SL RNA. Total RNA was prepared from cells carrying the PTB constructs before induction (-Tet), and after $3 \mathrm{~d}$ of induction (+Tet). Primer extension was performed on $10 \mu \mathrm{g}$ RNA with radiolabeled oligonucleotide complementary to the $3^{\prime}$ end of SL RNA (20708 listed in Supplemental Table S-1). cDNA was separated on a $6 \%$ sequencing gel. The position of stops resulting from the different cap nt is indicated on the left. Primer extension with U3 was used to control for the amount of RNA in the sample. (B) Primer extension to determine the level of Y structure intermediate. The same as in $A$ but the 9091 primer was used (listed in S-1). (C) Quantitative analysis of the SL RNA and the Y structure intermediate upon PTB silencing. The level of the SL RNA and Y structure in the uninduced cells is shown in gray bars, and the same values derived from three independent silencing experiments are given in white bars; the standard deviation is shown.

promoter. We next examined if the reduction in nascent SL RNA level may be a result of binding of these proteins to the nascent SL RNA, by in vitro UV-cross-linking of PTB1 protein to SL RNA synthesized in permeable cells. The results (data not shown) suggest that no such crosslinking can be observed when whole cell extracts were used. These results suggest that the effect of PTB on SL RNA levels is probably not primary, and may result from downregulation of an, as yet, unidentified factor that either functions in SL RNA transcription or stabilization of the nascent SL RNA.

\section{Microarray analysis of RNA isolated from PTB1 and PTB2 silenced cells suggests differential effects on the transcriptome}

Since the results presented in Figure 4 suggest that neither PTB1 nor PTB2 is a general splicing factor that affects the splicing of all mRNA, we sought to identify which mRNAs are specifically and differentially affected in cells depleted for PTB1 or PTB2. RNA was prepared from cells after $3 \mathrm{~d}$ of silencing and was compared with RNA from uninduced cells.

Three biological replicates were performed and hybridized to T. brucei microarrays described in Materials and Methods. The data were analyzed using GeneSpring GX software (Agilent Technologies). Lowess normalization was performed to correct for dye bias, and the normalized data were used to identify genes whose expression appeared to be significantly $(P$ value $<0.05)$ up- or down-regulated, with an arbitrary cutoff of at least 1.5-fold. A list of such genes is provided in Supplemental Table S-2. In order to visualize the differences in gene expression in the $P T B$ silenced cells, average linkage hierarchical clustering was performed on the selected genes using Pearson correlation as a similarity measure, and a heat map was constructed representing the difference in the level of transcripts between uninduced and silenced cells (Fig. 6). The results demonstrate that PTB1 and PTB2 differentially affect the transcriptome, suggesting that these proteins bind different subsets of mRNAs.

Since PTB1 and PTB2 affect not only splicing but also mRNA stability (see below), the list of regulated genes was

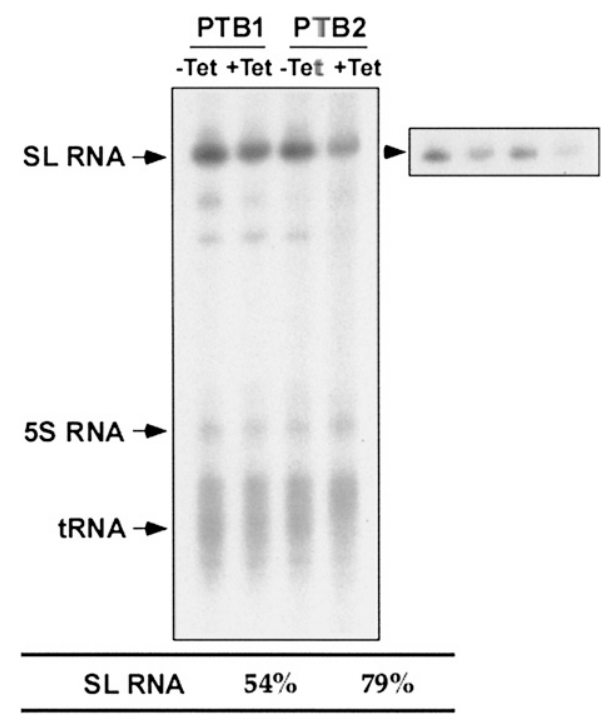

FIGURE 5. Nascent transcription in PTB1 silenced cells and PTB2 silenced cells. Permeable cells were prepared from the same number of uninduced and PTB silenced cells on the third day of silencing, as described in the Materials and Methods. The labeled RNA was fractioned on a $6 \%$ denaturing gel. The identities of the RNAs are indicated. A shorter exposure of the SL RNA is shown on the right. 


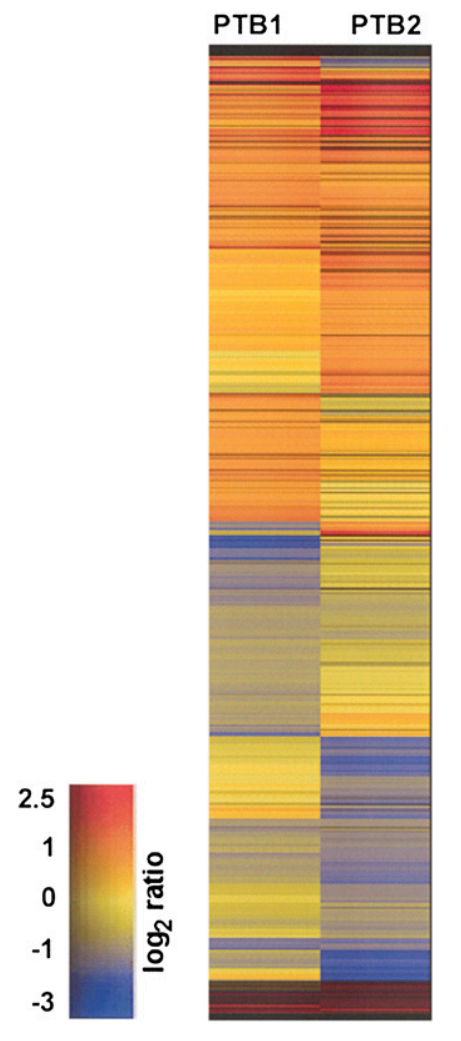

FIGURE 6. Heat map of genes that are differentially expressed between PTB1 and PTB2 silenced cells relative to uninduced cells. Transcripts that differ from the control by $>1.5$-fold change $(P$ value $<0.05)$ were chosen for the analysis. Each column represents the average of three biological replicates. The heat map was generated using Genspring GX software (Agilent technologies) using the average linkage hierarchical clustering algorithm and Pearson correlation as a similarity measure. The diagram represents the differential expression level according to the following color scale: red, up-regulated genes; blue, down-regulated genes.

screened for the presence of sequences rich in polypyrimidine tracts in sequences flanking the coding sequence at both the $5^{\prime}$ and $3^{\prime}$ ends of the ORF. To this end, $300 \mathrm{bp}$ upstream and $500 \mathrm{bp}$ downstream sequences of each gene were retrieved from the GeneDB using the "list download" tool (http://www.genedb.org). The search was performed using a $\mathrm{C}$ language program written in house (available from the authors upon request).

The program was designed to search for three types of sequences: (1) sequences carrying an optimal polypyrimidine tract (as a splicing signal), defined as a stretch of at least ten T's with only one C allowed (Benz et al. 2005); (2) polypyrimidine tracts that carry stretches of $\mathrm{T}$ and $\mathrm{C}$, where $\mathrm{T}$ is more abundant, and also contain PTB binding sites (TCTT and/or TCTCT); and (3) nonoptimal polypyrimidine tracts (as splicing signals) that lack PTB sequences, and in which $\mathrm{T}$ comprises at least $59 \%$ of the sequence (Benz et al. 2005). One hundred seventy genes were found to be down-regulated and 146 genes up-regulated by more than 1.5-fold in PTB1 silenced cells compared with control.
Of these, 49 out of the down-regulated genes and 36 of the up-regulated genes carry a nonconventional polypyrimidine tract (PPT) site containing a PTB binding site in their upstream region, and are presented in Supplemental Table S-3. 150 genes were down-regulated, and 214 genes were upregulated by more than 1.5-fold in PTB2 silenced cells compared with control. Of these genes, 46 out of the down-regulated genes and 51 out of the up-regulated genes lack a canonical PPT site, containing PTB binding sequences in their upstream region, and are presented in Supplemental Table S-4. The genes listed in Supplemental Tables S-3 and S-4 are most probably genes that are regulated at the splicing level, while the remaining transcripts are most probably regulated at the level of mRNA stability (see below). To examine if any transcripts are regulated by both PTB1 and PTB2, a Venn Diagram was prepared; the results indicate no significant overlap between the transcripts regulated by the two PTB proteins (data not shown), suggesting that each factor binds to a different subset of transcripts.

\section{Validation of the microarray data}

To validate the results obtained by the Microarray, several transcripts were selected from the list in Supplemental Table S-2 of potential PTB1 and PTB2 substrates that are either up- or down-regulated. cDNA was prepared from the RNA using random primers. The amount of the RNA in each sample was calibrated by examining the level of tubulin, a transcript whose level was not altered in PTB silenced cells. The candidates were selected based on their fold change during silencing (more than 2.3-fold), and only abundant mRNAs (based on the intensity of hybridization in microarray experiments) were analyzed. We also preferred to choose genes that have a clear annotation in the genome. The results in Figure 7A summarize the validation of five up-regulated transcripts and four down-regulated transcripts in PTB1 silenced cells, and those in Figure 7B summarize four up-regulated transcripts and five downregulated transcripts in PTB2 silenced cells. These results confirm that the microarray data indeed reflect true changes in the transcriptome as a result of PTB silencing, and that these transcripts are either down-regulated or upregulated as a result of $P T B$ depletion. To demonstrate the specificity of the effect on these distinct transcripts, the level of PTB1 substrates was examined in PTB2 silenced cells and vice versa. The results indicate that silencing of each of the PTB proteins specifically affected a unique subset of transcripts, again supporting the notion that these factors act on different substrates.

Next, we examined whether the down- or up-regulation is a direct result of binding of these factors to the cognate mRNAs. The binding of PTB was examined by immunoprecipitating the transcripts using antibodies to PTB1 and PTB2. To stabilize the mRNA-protein interactions, the cells 
A

\begin{tabular}{|c|c|c|}
\hline \multicolumn{3}{|c|}{ PTB 1} \\
\hline Accession no. & gene & \begin{tabular}{|cc} 
RT-PCR \\
- -Tet $\quad+$ Tet
\end{tabular} \\
\hline Tb10.6k15.0050 & PAG 5, Procyclin Associated gene 5 & $\cdots-$ \\
\hline Tb11.01.2690 & 2690 , Hypothetical gene & 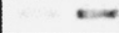 \\
\hline Tb11.22.0007 & 0007, Hypothetical gene & 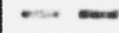 \\
\hline Tb09.160.3090 & hsp,1L12.440|heat shock protein & $\cdots \cdots$ \\
\hline Tb927.1.4540 & 4540 , hypothetical prote in & $-\infty$ \\
\hline & Tubulin & 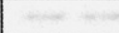 \\
\hline
\end{tabular}

\begin{tabular}{|l|l|l|l|}
\cline { 2 - 4 } & Tb927.7.190 & OPA, thimet oligopeptidase A & \\
\hline Tb09.160.5480 & TbNT10,purine nucleoside transporter & - \\
\hline \multirow{2}{*}{ Tb927.4.4730 } & AATP 11, amino acid trans porter & - \\
\hline \multirow{2}{*}{ Tb927.7.6070 } & Gresag. receptor-type adenylate cyclase 4 & \\
\hline & Tubulin & \\
\hline
\end{tabular}

PTB 2 RT-PCR -Tet + Tet
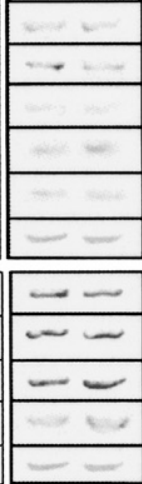

B

\begin{tabular}{|l|l|l|l|}
\hline Accession no. & \multicolumn{1}{|c|}{ gene } & $\begin{array}{c}\text { RT-PCR } \\
\text {-Tet +Tet }\end{array}$ & $\begin{array}{c}\text { RT-PCR } \\
\text {-Tet +Tet }\end{array}$ \\
\hline Tb927.8.3380 & ETP, electron transport protein & - \\
\hline Tb927.4.5310 & PKA,serine/threonine-protein kinase A & \\
\hline
\end{tabular}

\begin{tabular}{|c|c|c|}
\hline Tb927.6.1520 & $A Q P 3$, aquaporin 3 & $-\cdots$ \\
\hline Tb927.8.690 & PPI.peptidyl-prolyl cis-trans isomerase & -1 \\
\hline Tb927.8.550 & PMSR.peptide methionine sulfoxide reductase & $-\cdots$ \\
\hline Tb11.03.0870 & MCP,mitochondrial carnier protein & $-\cdots$ \\
\hline Tb11.02.1106 & NBT.nucleobase transporter & -- \\
\hline & Tubulin & 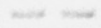 \\
\hline
\end{tabular}

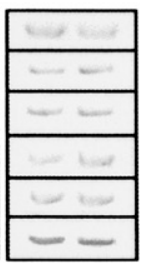

FIGURE 7. Validation of the microarray data by RT-PCR. cDNA was prepared from total RNA $(1 \mu \mathrm{g})$ derived from uninduced cells $(-$ Tet) or cells after $3 \mathrm{~d}$ of silencing (+Tet), as described in Materials and Methods. An aliquot of the cDNA (1/50 to 1/100) was amplified by PCR using the gene-specific primers (listed in Supplemental Table S-1). The PCR reaction was analyzed on 1\% agarose gels and visualized by ethidium bromide staining. The amount of cDNA was calibrated by measuring the amount of tubulin in the sample. For each reaction, we determined the linearity of amplification by diluting the cDNA. The genes presented are those that were significantly up-regulated or down-regulated during silencing (by at least 2.3-fold in the microarray data). As a control, the level of these transcripts was examined in RNA extracted from cells silenced for the other PTB. (A) Up-regulated and down-regulated genes in PTB1 silenced cells; $(B)$ as in A, but for PTB2 silenced cells. The accession number and annotation of each gene, based on GeneDB, are presented.

were exposed to UV irradiation, extracts were prepared from the cells, and the immunoprecipitated RNA was subjected to RT-PCR to detect the relevant transcripts. As a control, preimmune serum was used. The results presented in Figure 8 demonstrate selective binding of the PTB1 (Fig. 8A) and the PTB2 (Fig. 8B) to the cognate transcripts whose levels changed during silencing. Among the genes tested three proved to be false positives; in two out of the three (Tb927.4.5390 and Tb927.6.2640), their changes during depletion were also not confirmed by RT-
PCR. To verify the specificity of binding, PTB1 substrates were examined among the mRNAs immunoprecipitated by anti-PTB2 antibodies and vice versa. The results demonstrate complete specificity, since no PTB1 substrates were immunoprecipitated using anti-PTB2 antibodies and vice versa.

For each transcript, the change in the level of mRNA can stem from one or more mechanisms. PTB might affect the transcription of mRNA, the stability of the mRNA, or the splicing of the pre-mRNA. A decrease in the level of the transcript in silenced cells may suggest that PTB is essential for
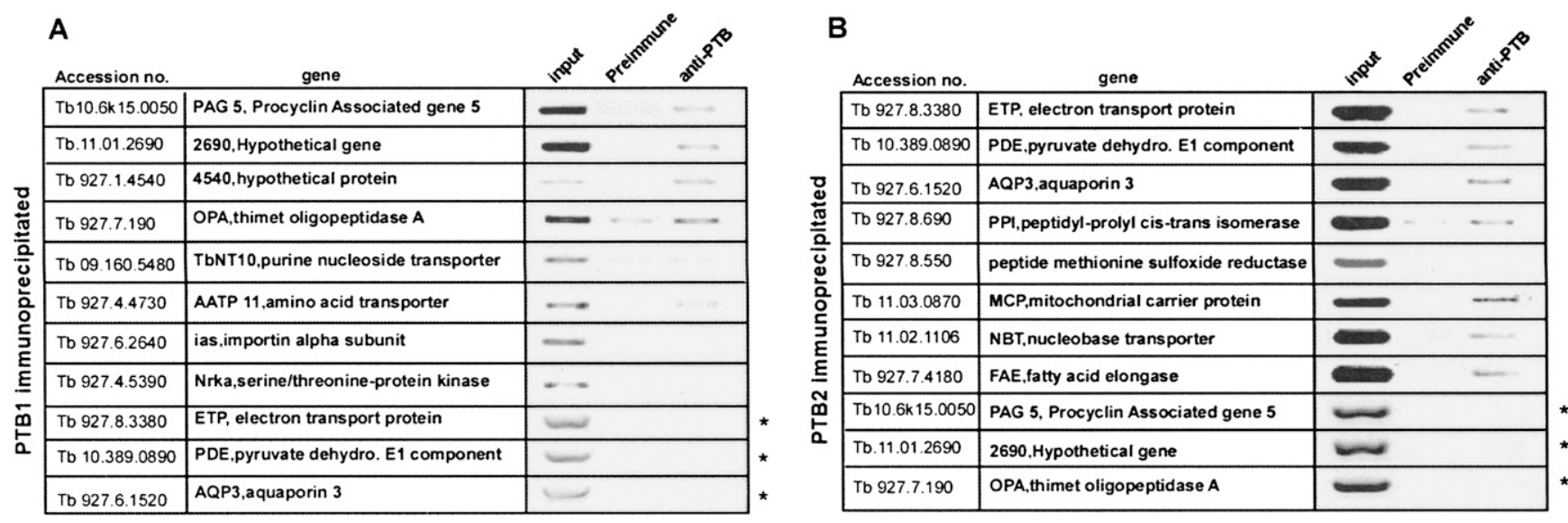

FIGURE 8. Identification of PTB1 and PTB2 substrates by immunoprecipitation with cognate antibodies. Whole cell extract was prepared from $5 \times 10^{9}$ parental cells after 5 min of UV cross-linking as described in Materials and Methods. Immunoprecipitation was performed with antiPTB1, anti-PTB2, or control-preimmune serum. RNA was eluted from the beads and, along with total RNA (input), was analyzed by RT-PCR. The primers used for amplification of the specific genes are listed in Supplemental Table S-1. The accession number and the annotation of the genes based on GenDB are presented. As a control, PTB2 substrates were examined in the PTB1 immunoprecipitated mRNAs and vice versa; these control transcripts are marked with asterisks. 
transcription, splicing, or transcript stabilization. However, we cannot rule out the possibility that the level of transcripts is also affected by secondary effects. For instance, one of the PTB targets may by itself be an RNA binding protein that affects the level of other substrates. However, no exact match to sequences present in the silencing construct exists in the genome that might silence a gene other than the PTB genes and hence generate an off-target effect.

Although transcriptional regulation (at the initiation level) does not seem to play a major role in gene regulation in trypanosomes, $P T B$ silencing affected the transcription of the SL RNA. It was therefore of interest to examine the effect of $P T B$ silencing on the transcription of protein coding genes, and compare it to the transcription of nonprotein-coding genes transcribed by polymerase I or III. PTB may bind to the DNA and affect transcription elongation. To examine whether $P T B$ silencing affects transcription, nascent RNA synthesized in permeable cells was used to probe slot blots carrying PCR products of transcripts that demonstrated changed levels in the PTB silenced cells. The results (Fig. 9) show that in both PTB1 silenced cells (Fig. 9A) and PTB2 silenced cells (Fig. 9B), the effect on nascent transcription of protein coding mRNAs was very modest compared with its effect on SL RNA transcription. Note that no change in transcription was observed for transcripts whose levels were elevated during silencing (marked with arrows). The results also demonstrate that transcription shut-off is most probably specific for polymerase II, since the most significant effect was seen for polymerase II transcripts, and no effect was observed on transcription of rRNA (transcribed by polymerase I) or U2 snRNA, which is transcribed in trypanosomes by poly-

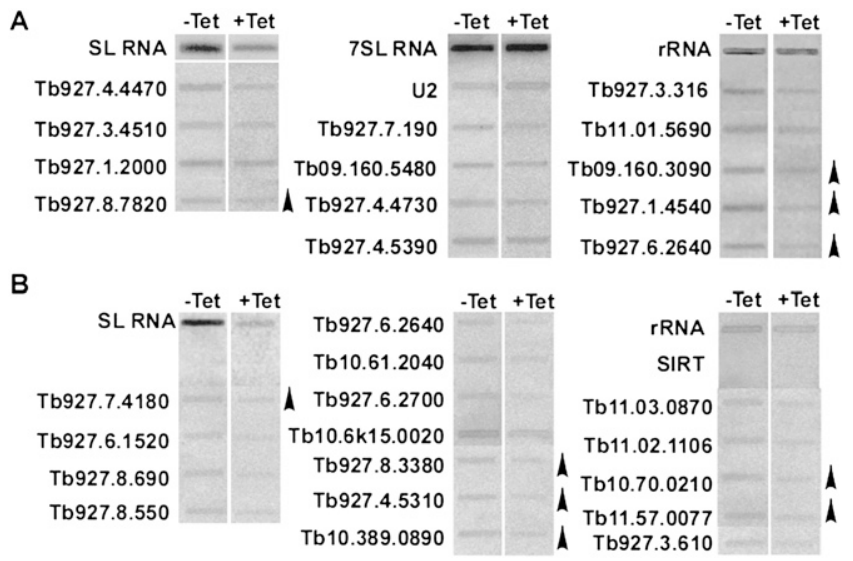

FIGURE 9. Nascent RNA synthesis in PTB1 and PTB2 silenced cells. Permeable cells were prepared from uninduced cells $(-\mathrm{Tet})$ and cells after $3 \mathrm{~d}$ of PTB1 and PTB2 silencing (+Tet) as described in Materials and Methods. RNA was used for hybridization with a slot blot containing DNA encoding the genes, as indicated. (A) PTB1; $(B)$ PTB2. The identity of the genes is given by their accession number. As a control, the mammalian SIRT gene was used. The up-regulated genes based on the array are indicated by arrows. merase III (Nakaar et al. 1994). However, we cannot rule out the possibility that PTB binds to particular DNA sequences along the genome and affects the transcription elongation of such loci. Nevertheless, we could not detect such loci in our limited screen for PTB substrates.

\section{PTB1 and PTB2 affect the stability of distinct sets of mRNAs}

In mammals, PTB was shown to govern the stability of mRNA by binding to the 3' UTR (Soderberg et al. 2002; Kosinski et al. 2003; Tillmar and Welsh 2004). To examine if PTB1 and PTB2 similarly regulate the stability of their substrates, the half-life of PTB1 and PTB2 target transcripts were examined. Two PTB1 targets were selected: AATP11 (Tb927.4.4730), which encodes an amino acid transporter whose expression is down-regulated upon PTB silencing, and a transcript encoding a hypothetical protein, HP2690 (Tb11.01.2690), whose level is up-regulated during silencing (Fig. 7A). For PTB2, the following transcripts were selected: AQP3 encoding a water channel aquaporin (Tb927.6.1520), which is down-regulated, and PDE (pyruvate dehydrogenase; Tb10.389.0890) whose level is upregulated in PTB2-silenced cells (Fig. 7B). To measure the half-life of the mRNA during silencing, uninduced cells and cells $3 \mathrm{~d}$ after induction were concentrated. After a few minutes of recovery, the cells were treated with sinefungin, which was shown to inhibit trans-splicing and to assist in shutting-off mRNA production; hence, this agent improves the quality of experiments that determine the half-life of mRNAs (Colasante et al. 2007). Sinefungin was added to the cells for $10 \mathrm{~min}$, then actinomycin D was added, and RNA was extracted from the cells at the indicated time points. Northern analysis was performed using the indicated probes. The same membranes were hybridized with a probe specific to 7SL RNA. The level of the mRNAs was measured by densitometry, and the half-life was calculated normalizing to the level of 7SL RNA. As can be seen in Figure 10A, the half-life of AATP11 mRNA was decreased from 43 to $22 \mathrm{~min}$, whereas the half-life of HP2690 was increased from 10 to $100 \mathrm{~min}$ in PTB1 silenced cells. The half-life of $A Q P 3$ was decreased from $80 \mathrm{~min}$ to $20 \mathrm{~min}$, and that of PDE was increased from $40 \mathrm{~min}$ to $75 \mathrm{~min}$ in PTB2 silenced cells (Fig. 10B). The results in Figure 10 were repeated three times and each time point is shown with its corresponding standard deviation. These results suggest that both PTB proteins affect the stability of mRNAs either by stabilizing or destabilizing them. Interestingly, the fold change in AATP11 levels in silenced cells exceeds the observed change in the half-life of the corresponding mRNA, suggesting that PTB may exert its regulation on this transcript via additional mechanism(s) (see below).

These results show that the transcripts are differentially affected, with the amplitude of regulation ranging from a two- to 10-fold difference. However, PTB1 and PTB2 


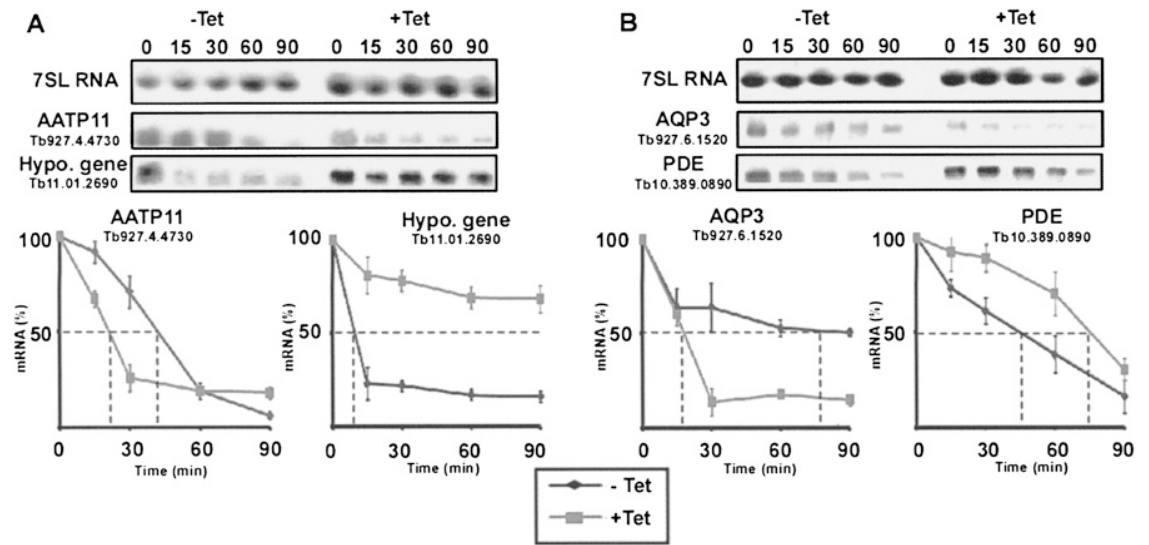

FIGURE 10. PTB1 and PTB2 regulate the half-life of mRNAs. Northern analysis of mRNA levels. Uninduced and PTB1 depleted cells ( $3 \mathrm{~d}$ after induction) were treated with sinefungin (2 $\mu \mathrm{g} / \mathrm{mL})$ and, after $10 \mathrm{~min}$, with Actinomycin D $(30 \mu \mathrm{g} / \mathrm{mL})$. RNA was prepared at time points indicated above the lanes, separated on a $1.2 \%$ agarose-formaldehyde gel, and subjected to Northern analysis with the indicated gene-specific probes. 7SL RNA was used to control for equal loading. (A) PTB1; (B) PTB2. The hybridization signals shown in the upper panel were measured by densitometry. The decay curves are shown below the blots, and the half-life is illustrated by the broken lines. The decay in the absence of induction ( - Tet) is indicated by black diamonds; upon induction (+Tet), by gray squares.

proteins should recognize a PPT domain enriched with PTB binding sites; thus the cognate transcripts are expected to contain such sites, and a consensus-binding site should exist. To search for such sequences, a multiple alignment was performed using ClustalW (http://npsa-pbil.ibcp.fr/ cgi-bin/npsa_automat.pl?page=/NPSA/npsa_server.html). A series of 41 transcripts carrying PPT sequences that were affected in PTB1 silenced cells and 98 transcripts that were affected in PTB2 silenced cells were chosen for the analysis. Since these binding sites were readily detected at the $3^{\prime}$ UTR, only $3^{\prime}$ UTR sequences were used to generate the data set. The sequence alignment is presented in Supplemental Table S-5. The highlighted sequences contain one or two PTB binding sites imbedded in the PPT.

\section{PTB1 and PTB2 are essential for trans-splicing of transcripts carrying $\mathrm{C}$ rich polypyrimidine tracts}

As indicated above, transcripts such as AATP11 were down-regulated beyond the effects that could be attributed to mRNA stability, suggesting that PTB may also operate at the level of splicing. This observation led us to inspect the $5^{\prime}$ UTR of genes that were down-regulated as a result of PTB1 or PTB2 silencing. We identified transcripts that lack a consensus PPT, having mostly U's, but possess PTB sites that are C-rich. Six transcripts were chosen, and their AG splice site was determined by amplifying the specific mRNA using RT-PCR with an anti-sense primer situated close to the first AUG and SL sense primer. The sequence upstream to the AG splice site of six genes is shown in Figure 11A; the putative PPT are boxed and italicized. Inspection of the sequences suggest that in these transcripts, the distance between the AG and the PPT is $10-60$ nucleotides (nt), which in most cases, is longer than the average of $25 \mathrm{nt}$ previously observed (Benz et al. 2005). The ratio of $\mathrm{U} / \mathrm{C}$ is 1.52 compared with 2 found in the majority of the transcripts (Benz et al. 2005). In addition, a PTB binding site was found imbedded in each of the PPT sites. To examine if the trans-splicing of these transcripts is affected under PTB silencing, the levels of the mature and pre-mRNA were determined upon PTB silencing by RT-PCR. Since U2AF65 binds to PPT sites (Zamore et al. 1992), it was of interest to determine if the trans-splicing of these PPT C-rich transcripts is also dependent on the presence of U2AF65. The T. brucei U2AF65 was recently described and is larger than its mammalian homolog. It interacts with SF1 but not with U2AF35 and affects the first step of the trans-splicing reaction (Vazquez et al. 2009). To this end, the trans-splicing of the six transcripts were examined in PTB1 silenced cells, PTB2 silenced cells, and U2AF65 silenced cells. The results (Fig. 11B) suggest that in five of the transcripts, transsplicing was perturbed in PTB1 silenced cells or PTB2 silenced cells, suggesting that the trans-splicing of these transcripts depends on the presence of PTB1 or PTB2. To control for specificity and the amount of RNA used in the reactions, we used tubulin mRNA as a control, since the level of this transcript does not change upon PTB1 or PTB2 silencing. For U2AF65, the level of 7SL RNA was used for normalization, since U2AF65 is a general splicing factor that affects the trans-splicing of all genes. The results in Figure 11 therefore suggest that PTB proteins function in addition to, and not instead of, U2AF65, since transsplicing of the same six transcripts required the presence of functional U2AF65 for proper trans-splicing.

Since in mammals, PTB is a splicing repressor, we searched the data set of up-regulated genes for genes that carry a C-rich PPT site. One such transcript (number 6 in the list, Tb11.01.3580) was identified, and indeed, silencing of PTB1 enhanced its trans-splicing, suggesting the PTB1 can serve as either a splicing repressor or activator. Many more such transcripts may exist among transcripts that have a PTB binding sites in their PPT, and whose level is up-regulated during silencing.

\section{Identification of the AATP11 PTB1 binding sites in vivo and in vitro}

To verify that $\mathrm{PTB}$ binds to the putative binding sites indicated in Figure 11A, the AATP11 substrate was used for 


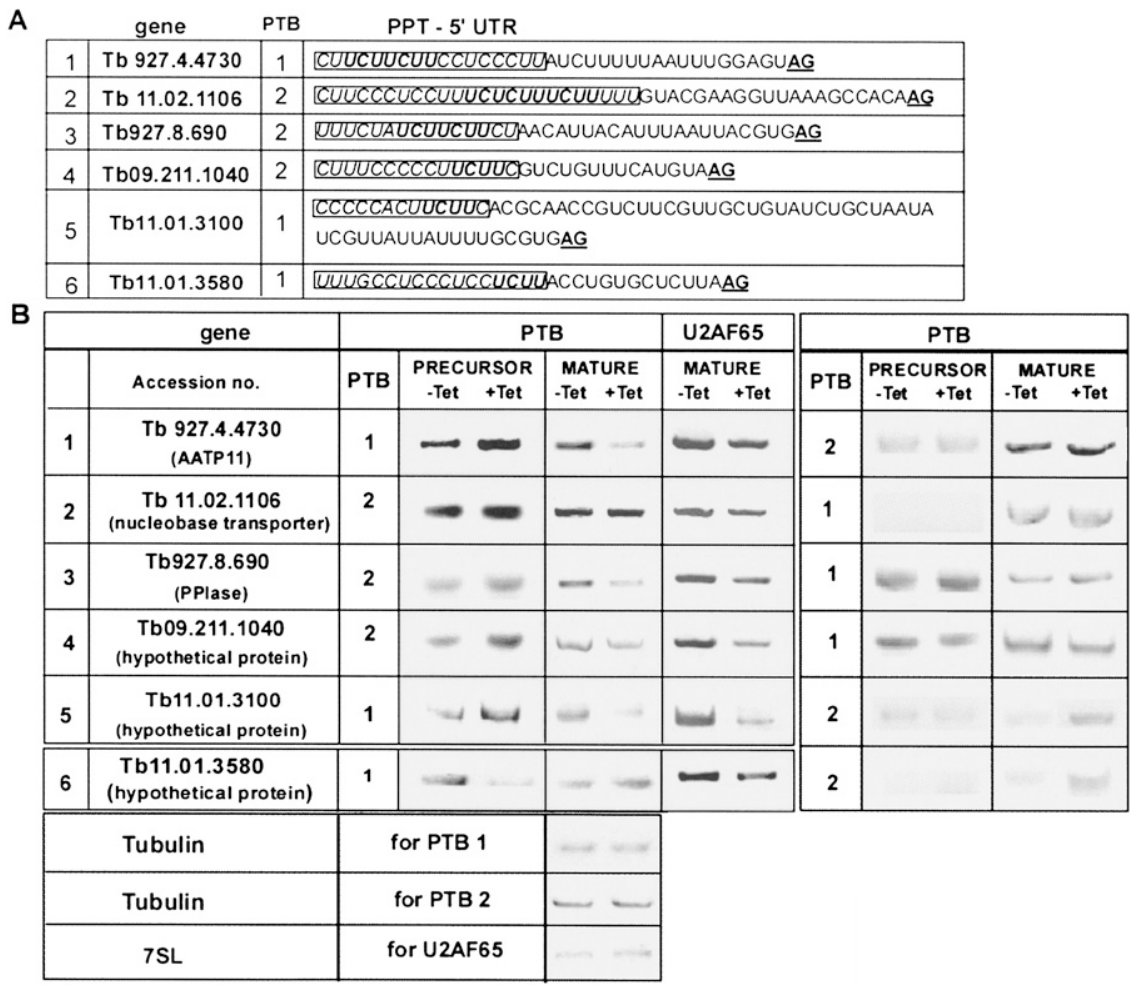

FIGURE 11. Analysis of genes whose trans-splicing is regulated by the PTB proteins. $(A)$ The sequence upstream to the AG splice site is indicated, and the sequences of the AG are bold and underlined, the PPT sequence italicized and boxed, and the putative PTB binding sites within the PPT sequences are in bold. The accession number and regulation by either PTB1 or PTB2 are indicated. $(B)$ RT-PCR to determine the level of pre-mRNA and mature mRNA under PTB1, PTB2, and U2AF65 silencing. cDNA was prepared from uninduced cells or from cells after $3 \mathrm{~d}$ of silencing. The calibration of the amount of cDNA was performed using the tubulin gene. RT-PCR was performed as described in Materials and Methods. The primers used to amplify the pre-mRNA and mature RNA are listed in Supplemental Table S-1. The PCR products were separated on $1 \%$ agarose gels and stained with ethidium bromide. The accession numbers of the genes are given. As a control for the amount of cDNA in each sample, the amount of tubulin was determined for RNA from PTB1 and PTB2 silenced cells, and the amount of 7SL RNA in RNA from U2AF65 silenced cells.

further analysis. Recent studies suggest that this gene is highly expressed in the procyclic stage of the parasite and is regulated via mRNA stability, dictated by sequences present in the 3' UTR of the gene (Robles and Clayton 2008). The sequence of AATP11 and the position of the PPT relative to the AG splice site are presented in Figure 12A (EST AF009707). An RNase protection assay was performed to examine trans-splicing defects of AATP11 in PTB1 silenced cells. The results (Fig. 12B, panel c) demonstrate accumulation of the precursor and reduction in the mature AATP11 as a result of PTB1 silencing.

Next, the $5^{\prime}$ flanking sequences of AATP11 were cloned into the pNS21b vector (64 nt of $5^{\prime}$ UTR) with an additional $260 \mathrm{nt}$ upstream of the AG splice site, which carries the signals essential for trans-splicing of the gene. The vector therefore contains a luciferase gene, whose expression depends on the $5^{\prime}$ flanking sequences of the AATP11 gene (Fig. 12B, panel b). The transcript is expressed from the strong EP promoter (Siegel et al. 2005), and the $3^{\prime}$ UTR sequences are derived from the EP gene. Since the fused transcript lacks the authentic 3' UTR of the AATP11 gene, the effect on expression observed in this study depends solely on the binding of PTB to the AATP11 PPT site.

To verify that the sequence present 10 nt upstream of the AG splice site and carrying the PTB binding site is indeed the site that governs the splicing regulation of AATP11 by PTB1, the C's in this site were converted to U's thereby destroying the PTB binding sites. The structure of the construct is shown in Figure $12 \mathrm{~B}$, panel $\mathrm{b}$, and the location of the mutations introduced in the PPT site is shown in Figure 12A. Transgenic parasites carrying the reporter gene as well as the stem-loop construct to silence PTB1 were generated. The processing of the AATP11 transcript-fused to luciferase was examined by RNase protection. The results presented in Figure $12 \mathrm{~B}, \mathrm{~d}$, demonstrate that like the wild-type gene, the AATP11-luciferase splicing was dependent on PTB1, since in silenced cells, a reduction in mature RNA and the accumulation of precursor were observed. However, the regulation by PTB1 was lost in cells carrying the mutated PPT tract, since the mutated AATP11 transcript did not show any dependence on PTB1 for splicing (Fig. $12 \mathrm{~B}, \mathrm{e})$. In fact, mRNA levels were not reduced but slightly elevated. These data suggest that the PPT carrying the PTB binding site and rich in C's are indeed the binding sites that confer PTB1 regulation on AATP11.

To examine the direct binding of PTB to the AATP11 substrate, the pre-mRNA was incubated with either recombinant PTB1 or whole cell extract and exposed to UV cross-linking. After RNase digestion, the radioactivity remains associated with only proteins that were bound to the labeled RNA. The results of such an experiment are presented in Figure 12C. One of the proteins that became cross-linked to AATP11 is PTB1, as a protein migrating with the same molecular weight as recombinant PTB1 was identified when pre-mRNA was cross-linked to proteins present in whole cell extract. The identification of the PTB1 band in whole cell extract was verified by Western analysis (Fig. 12C, left panel). In addition, the cross-linking to this protein (marked with an arrow) was reduced when unlabeled pre-AATP11 was added to the reaction (reduction to 
A

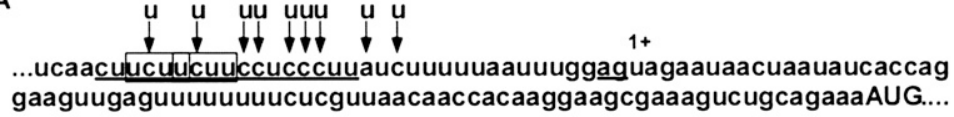

B ${ }^{a}$

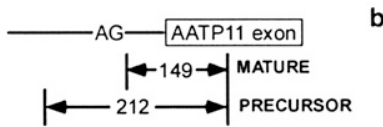

b

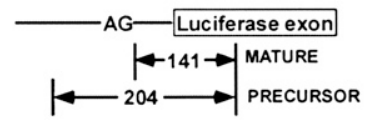

c

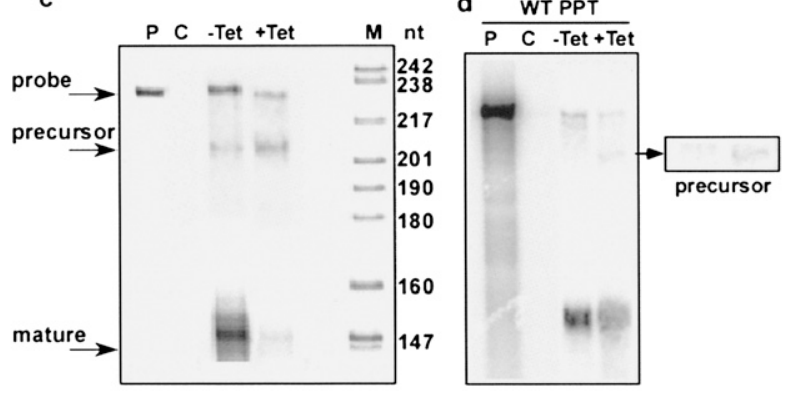

$\frac{\text { WT PPT }}{\text { P } \quad \text { C -Tet }+ \text { Tet }}$

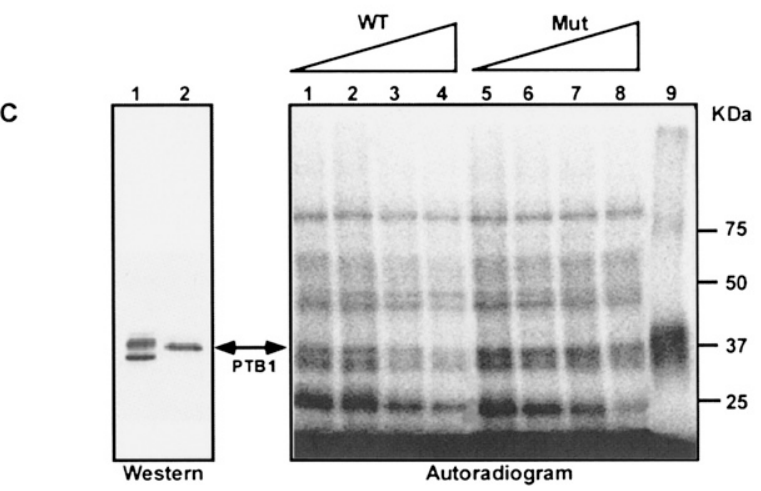

FIGURE 12. In vivo and in vitro analysis of $A A T P 11$, a gene whose splicing is regulated by PTB1. (A) Schematic representation of the AATP11 transcript. The AG splice and the PPT are underlined. The base-substitutions introduced into the PPT are indicated with arrows. $(B)$ RNase protection of AATP11 transcript. Schematic representation of the probes used for RNase protection of the premature and mature AATP11 transcripts. (Panel $a$ ) The probe used to protect the wild-type transcript; the expected size in nucleotides of the mature, and precursor protected fragments are indicated. (Panel $b$ ) Schematic representation of the probe used to protect the AATP11 $5^{\prime}$ regulatory unit fused to luciferase gene. The sizes of the mature and protected fragments are indicated. (Panel $c$ ) Protected fragments of the AATP11 wild-type transcript. RNA was subjected to RNase protection as described in Materials and Methods, and the products were separated on a $6 \%$ acrylamide $-7 \mathrm{M}$ urea gel. The protected fragments from uninduced cells (-Tet) and cells after $3 \mathrm{~d}$ of induction (+Tet) of PTB1 are presented. P indicates probe; $\mathrm{C}$, control (no RNA was added to the RNase digestion mix); and $\mathrm{M}$, marker (end-labeled pBR322 MspI digest). The positions of the precursor and mature AATP11 are indicated. (Panel $d$ ) RNase protection of AATP11-luciferase fused transcript. RNA was prepared from transgenic parasites expressing the luciferase gene from the AATP11 5' regulatory unit (pNS21b). Expression was monitored in PTB1 cells after $3 \mathrm{~d}$ of silencing. The protected fragments were separated on a 6\% acrylamide-7 $\mathrm{M}$ urea gel. A longer exposure of the protected fragment is presented and indicated by arrows. $\mathrm{P}$ indicates probe; $\mathrm{C}$, control (no RNA was added to the RNase protection assay). (Panel $e$ ) RNase protection on AATP11luciferase fused transcript carrying a PPT mutation. The same as in $d$ but the RNA was prepared from cells carrying the PPT mutation. $(C)$ Proteins that become cross-liked to the AATP11 transcript and to the transcript carrying mutations in the PPT site. (Right panel) Cross-linking was performed as described in Materials and Methods, using whole cell extracts in the presence of increasing amounts of unlabeled, nonradioactive, competitor AATP-11 transcript. (Lanes 1-4) Increasing amounts of unlabeled wild-type AATP-11 (0, 50, 100, 200 ng, respectively); (lanes 5-8) increasing amounts of unlabeled, nonradioactive AATP-11 carrying the PPT mutation (0, 50, 100, $200 \mathrm{ng}$, respectively); (lane 9) cross-linking with recombinant PTB1. (Left) Western analysis. The cross-linked material was subjected to Western analysis with anti-PTB1 antibodies. (Lane 1) Cross-linking using recombinant protein (50 ng); (lane 2) cross-linking using whole cell extract. The size of the protein marker is indicated.
$24 \%$ binding upon adding of 200 molar excess of the unlabeled RNA), but not when unlabeled mutated AATP11, lacking the PTB sites, was used for competition (reduction to $85 \%$ binding upon adding 200 molar excess of the unlabeled RNA) (Fig. 12C). These results clearly show direct binding of PTB to the AATP11 substrate at the proposed PTB1 binding site. Note, that such binding to AATP11 was also detected when anti-PTB1 antibodies were used to immunoprecipitate PTB substrates (Fig. 8A).

\section{PTB1 but not PTB2 is essential for cis-splicing}

Since PTB was shown to affect cissplicing in mammals and was shown not only to bind to the PPT upstream to the $3^{\prime}$ splice site but also to the $5^{\prime}$ splice site region, we examined whether PTB is also essential for cis-splicing. To this end, two known substrates that undergo cis-splicing were examined. The results in Figure 13 demonstrate by RT-PCR (using tubulin to control for the amount of RNA) that splicing of both poly A polymerase (PAP) and ATPdependent DEAD/H RNA helicase $(A D R H)$ were affected in the silenced cells, since in both genes, reduction of the mature RNA was observed, with clear accumulation of the precursor. Inspection of the PPT of these genes suggests that their sites are conventional. The presence of a PTB binding site was observed either near the $5^{\prime}$ splice site, in the case of $P A P$, or in several positions in the intron, in the case of ADRH (see Supplemental Table S-6). Interestingly no effect on cis-splicing was observed in PTB2 silenced cells (Fig. 13).

\section{DISCUSSION}

In this study, we investigated the role of two trypanosome homologs of the mammalian PTB protein. Both proteins were shown to affect mRNA stability and trans-splicing. PTB1 was also shown to be essential for cis-splicing. Thus, our results suggest that PTB 


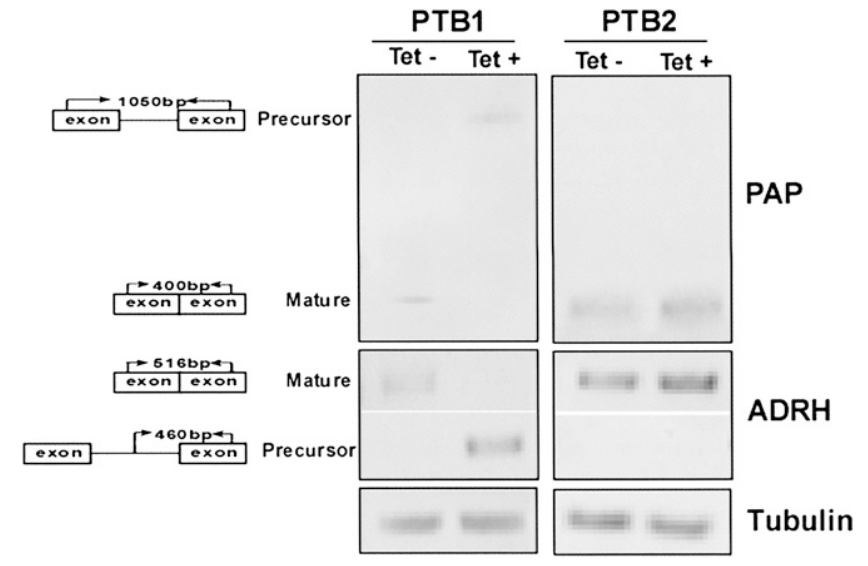

FIGURE 13. Cis-splicing of poly A polymerase (PAP) and ATPdependent DEAD/H RNA helicases $(A D R H)$ is regulated by PTB1 but not by PTB2. Levels of PAP and ADRH precursor and mature mRNA detected by RT-PCR. cDNA was prepared as described in Materials and Methods. cDNA was used for PCR analysis with the primers listed in Supplemental Table S-1. Schematic representation of the primers used in the reaction and expected PCR products are illustrated on the left. The PCR reactions were analyzed on a $1 \%$ agarose gel. (Left) Analysis of PTB1 silenced cells. cDNA from uninduced cells (-Tet), and cDNA from PTB1 silenced cells $3 \mathrm{~d}$ after induction (+Tet). (Right) Analysis of PTB2 silenced cells. cDNA from uninduced cells (-Tet), and cDNA from PTB2 silenced cells $3 \mathrm{~d}$ after induction (+Tet). The level of tubulin transcript was used to control for the amount of cDNA in each sample.

proteins in a unicellular organism play a major role in mRNA processing, as they do in mammals.

\section{PTB silencing results in a complex phenotype affecting the transcription of SL RNA but not of mRNAs}

Silencing of the two PTB proteins enabled us to observe major changes in the transcriptome of the parasites. However, the effect of PTB1 and PTB2 silencing on transcription was most noticeable for SL RNA. ChIP assay did not show any specific binding of the PTB proteins to the SL RNA promoter (data not shown). We also were not able to demonstrate binding of PTB to SL RNA by UVcross-linking in cell extracts (data not shown). Thus, if PTB interacts with SL RNA during transcription, the interaction must be transient and hence difficult to capture. Thus, the main effect of PTB depletion on SL RNA transcription might be indirect. For instance, among the PTB substrates that are deregulated, transcript(s) may exist that encode short-lived proteins that are essential for SL RNA transcription or stabilization of the nascent transcript.

The transcription of the protein coding genes was not significantly perturbed in the silenced cells compared with control cells, even for transcripts whose steady-state level was elevated in the silenced cells (Fig. 9), suggesting that there is no major defect in transcription of the genes tested. It is still possible that PTB proteins are associated with
DNA sequences along the chromosomes and that their DNA binding may affect transcription elongation. It will therefore be of great interest to perform a ChIP on chip analysis using the antibodies we generated in order to determine if the PTB proteins bind to DNA sequences and affect transcription elongation.

\section{PTB1 and PTB2 regulate mRNA stability}

Much information is available regarding the sequence in the 3' UTR of trypanosome genes (Clayton and Shapira 2007), but the regulatory proteins that bind them have not been identified to date. The only RNA binding proteins that were identified so far are two small RRM-containing proteins, TcUBP1 and TcUBP2, that are involved in downregulation of mucin mRNA in T. cruzi (D'Orso and Frasch 2002). Here, we show that both PTB1 and PTB2 function to control mRNA stability by either increasing or decreasing the half-life of the target mRNAs. The mRNAs that are destabilized during PTB silencing may carry hypersensitive sites to endonucleases at their $3^{\prime}$ UTR that are protected in the presence of PTB, but not in the silenced cells. For the mRNAs that are up-regulated during silencing, PTB most probably recruits the degradation machinery that exists in trypanosome (for review, see Clayton and Shapira 2007). How can the same proteins stabilize or destabilize different mRNAs? The dual effects might solely depend on the binding of additional factors. Indeed, the binding site that dictates mRNA stability was repeatedly mapped to $\sim 100$-nt domains from the termination codon and may have a distinct secondary structure and room for the interactions with several factors (Clayton and Shapira 2007). The combinatorial interactions of PTB with other RNA binding proteins may generate a multitude of complexes, each formed under different physiological or developmental conditions. Note that mammalian PTB1 was also shown to regulate mRNA stability. However, in all cases, PTB was shown to stabilize the target mRNA and lead to upregulation of gene expression (Kosinski et al. 2003; Soderberg et al. 2002; Tillmar and Welsh 2004). In trypanosomes, both PTB proteins can either stabilize or destabilize their mRNA targets.

\section{PTB1 and PTB2 are required for the trans-splicing of only a subset of mRNAs}

Analysis of the level of $\mathrm{Y}$ structure intermediate upon silencing of PTB1 and PTB2 suggests that these proteins are not general splicing factors. We have previously demonstrated that silencing of general splicing factors such as Sm (Mandelboim et al. 2003), Lsm (Liu et al. 2004), and PRP31 or PRP43 (Liang et al. 2006) affects the level of the Y structure. We also showed that Prp43 leads to accumulation of the $\mathrm{Y}$ structure, because splicing is inhibited in the second step, whereas in the case of the other factors (Sm, 
Lsm, PRP31) splicing is perturbed in the first step, leading to a decrease in the $\mathrm{Y}$ structure intermediate. Although, in this study, we provide evidence that PTB is essential for trans-splicing of certain genes, the number of these genes is small, and these defects are unlikely to be detected when examining the overall level of the Y structure intermediate.

We noticed that all the genes whose splicing was regulated by PTB carried a noncanonical PPT. Although we focused mainly on genes that require PTB1 or PTB2 for splicing, we also verified the existence of a single gene (Tb11.01.3580) in which splicing is repressed by PTB1 (Fig. 11). This transcript lacks the PTB binding site in the $3^{\prime}$ UTR, and its regulation by PTB relies on the existence of PTB sites within its potential PPT. In fact, there are additional substrates that contain PTB sites in the PPT whose level is up-regulated in the PTB silenced cells, and hence their splicing might be repressed. Our study is the first to show that different transcripts require additional factors for their trans-splicing. We still do not know the minimal requirements for a substrate to be efficiently transspliced in vivo. The efficiency by which factors such as U2AF35 bind to the $3^{\prime}$ splice site, U2AF65 to the PPT, and SF1 to the branch site must contribute to the overall efficiency of the reaction. However, the binding of the U2AF complex can be greatly enhanced in mammals by factors such as SR and hnRNP proteins (Smith and Valcarcel 2000). The presence in trypanosomes of SR and hnRNP proteins such as hnRNP H/F already suggested that trans-splicing might be regulated by such factors (Liang et al. 2003). Here, two types of regulation were revealed: splicing that requires an additional factor such as PTB proteins and splicing that is inhibited by the binding of the same PTB factor. As discussed above, many hnRNP proteins in metazoa function as splicing repressors or activators depending on the site on the pre-mRNA at which these factors bind and what other protein factor(s) interact with the factor and the RNA (Martinez-Contreras et al. 2007). The ability to acquire such a regulation requires both the appearance of RNA binding proteins and suitable RNA binding sites that can differentially bind such proteins. The PPT is an excellent site to use for acquiring such regulation. Indeed, we show that transcripts carrying a C-rich PPT need PTB for efficient trans-splicing. Based on this observation, one can envision that the splicing of these genes can potentially be regulated by the availability of PTB1 and PTB2 or alternatively the posttranslational modification of the proteins. Indeed, many splicing factors were shown to be regulated by phosphorylation and dephosphorylation (Stamm 2008). However more work is needed to establish if these proteins undergo phosphorylation under certain conditions. If PTB can be regulated by post-translation modification induced by signaling cascades, this can provide a mechanism to regulate hundreds of transcripts of the trypanosome transcriptome.

\section{The role of PTB proteins in mammalian and in trypanosome splicing}

In mammals, PTB was shown to act mainly as a splicing repressor, and several models were suggested to explain its role. These models suggest either direct competition of PTB with U2AF65 binding to the PPT, or looping out of the exon and sequestering the binding sites of relevant splicing factors (Wagner and Garcia-Blanco 2001; Oberstrass et al. 2005). Most recently, it was suggested that PTB interferes with the process of either intron or exon definition, which are essential for activating the splicing process. It was demonstrated that PTB controls the transition from exon definition to intron definition (Sharma et al. 2008). It was further suggested that PTB may interfere with the stimulatory cross-talk between U1 snRNP and U2AF65, preventing the U2AF65 activation by U1 snRNP.

The models that explain the function of PTB in mammals cannot be easily extended to trypanosomes. However, it is possible that PTB functions to activate/strengthen the interactions between U1 snRNP and U2AF65 in trypanosome cis-splicing introns (Fig. 13). Therefore, PTB may avoid or inhibit the trans-splicing of an AG splice site that needs to be utilized for cis-splicing. Studies suggest that PTB also can regulate polyadenylation by interacting with CstF64 (Le Sommer et al. 2005). If this is the case, and since trans-splicing was shown to be linked to polyadenylation (LeBowitz et al. 1993; Hug et al. 1994; Matthews et al. 1994), it is possible that PTB can also regulate the level of the transcript by affecting the cross-talk between the splicing and the polyadenylation machineries.

In mammals, there is a single PTB protein, and several variants of this protein exist (Wagner and Garcia-Blanco 2001). In trypanosomes, two proteins that bind to the PPT were identified in this study. Both proteins seem to bind more to the substrates with PTB sites in the $3^{\prime}$ UTR than the $5^{\prime}$ UTR, suggesting that these factors have a major role in mRNA stability.

In sum, PTB proteins exhibit the same complex regulation in trypanosomes and in higher eukaryotes, suggesting that alternative regulated splicing is a very ancient property of the splicing machinery, and regulates both cis- and transsplicing.

\section{MATERIALS AND METHODS}

\section{Cell growth and transfection}

Procyclic T. brucei strain 29-13 (obtained from the laboratory of Paul Englund, Johns Hopkins University; a gift from the group of George Cross, The Rockefeller University), which carries integrated genes for T7 polymerase and the tetracycline repressor, was grown in SDM-79 medium supplemented with 10\% fetal calf serum in the presence of $50 \mu \mathrm{g} / \mathrm{mL}$ hygromycin and $15 \mu \mathrm{g} / \mathrm{mL}$ G418. Cells were transfected as previously described (Mandelboim et al. 2003). For cloning, the transfected cells were diluted into 
microtiter plates in the presence of the parental T. brucei 29-13, which served as feeder cells. After $2-3 \mathrm{wk}$, clonal populations were obtained in the microtiter plates, and the cells were transferred to medium for propagation. Cells from cultures that showed typical growth arrest upon tetracycline induction were grown and frozen. Every $2 \mathrm{wk}$, a new culture was started from the original frozen stock.

\section{Construction of RNAi, TAP-tagged, and GFP fusions of the PTB proteins}

The stem-loop constructs for silencing PTB1 and PTB2 were established as described (Wang et al. 2000). A 479-bp (PTB1) or 443-bp (PTB2) fragment of the coding region was used to generate the stem-loop constructs using primers listed in Supplemental Table S-1. The constructs expressing dsRNA were linearized with EcoRV and transfected into the 29-13 parental cell line; the transformants were selected with $5 \mu \mathrm{g} / \mathrm{mL}$ phelomycin and cloned by limited dilution. The expression of dsRNA was induced using $8 \mu \mathrm{g} / \mathrm{mL}$ tetracycline.

To generate the TAP-tagged versions, the genes were amplified with the primers listed in Supplemental Table S-1. The fragments were cloned into pLew79-MHTAP (Schnaufer et al. 2003). The plasmids were linearized with NotI.

To generate the PTB1GFP-fused proteins, the gene was amplified with a forward primer carrying the SphI site (two nucleotides were added to maintain the ORF and a reverse primer carrying the XbaI site [listed in Supplemental Table S-1]). The product was cloned into a pUC19 vector carrying the GFP. The pUC19-GFP was generated as described (Tkacz et al. 2007). The plasmids were linearized with MluI.

\section{Northern analysis}

Total RNA was prepared with TRI reagent (Sigma), and the 20 $\mu \mathrm{g} / \mathrm{lane}$ was fractionated on a $1.2 \%$ agarose, $2.2 \mathrm{M}$ formaldehyde gel and transferred to a nylon membrane (Hybond, Amersham Biosciences). The RNA was visualized with ethidium bromide. After cross-linking and baking at $80^{\circ} \mathrm{C}$ under vacuum for $1 \mathrm{~h}$, the membrane was hybridized with a randomly labeled DNA probe (Random Primer DNA Labeling Mix, Biological Industries Co.) at $42^{\circ} \mathrm{C}$ and washed twice for $20 \mathrm{~min}$ each at $50^{\circ} \mathrm{C}$, with $2 \times$ SSC, $0.1 \%(\mathrm{w} / \mathrm{v})$ SDS.

\section{Semi-quantitative RT-PCR}

Total RNA was extensively treated with a DNase-based DNA inactivation reagent (DNA-free; Ambion) to remove the DNA contamination. Reverse transcription was performed using $1 \mu \mathrm{g}$ of total RNA with $0.2 \mu \mathrm{g}$ of random hexamer primer (Fermentas Revert Aid First Strand cDNA Synthesis Kit). Next, the cDNA was used in PCR amplification. To compare the level of expression of different genes, the amount of cDNA in the samples was calibrated by determining the level of tubulin mRNA, since the level of this mRNA was not altered during silencing of the PTB proteins. The amount of PCR product produced was linear with the dilution of the cDNA.

\section{Primer extension analysis}

Total RNA was prepared from T. brucei cells using TRI reagent (Sigma). Primer extension analysis was performed as described
(Xu et al. 2001) using 5'-end-labeled oligonucleotides specific to target RNAs. The extension products were analyzed on $6 \%$ polyacrylamide-7 M urea gel and visualized by autoradiography.

\section{mRNA stability analysis}

Uninduced cells and cells $3 \mathrm{~d}$ after induction $\left(1.5 \times 10^{9}\right.$ cells $)$ were concentrated and resuspended into $25 \mathrm{~mL}$ of the SDM-79 medium. Cells were aliquoted into five batches and incubated for $30 \mathrm{~min}$ at $27^{\circ} \mathrm{C}$. Cells were pretreated with $2 \mu \mathrm{g} / \mathrm{mL}$ sinefungin (Sigma) for $10 \mathrm{~min}$, and then with $30 \mu \mathrm{g} / \mathrm{mL}$ Actinomycin D (Sigma). Aliquots were taken at different time points (0-90 min). For each time point, total RNA was prepared and the samples were subjected to Northern analysis. Quantitation by densitometry was performed on the hybridization signals, and the results were used to calculate the half-life of the mRNAs.

\section{In vivo transcription/permeable cells/slot blot}

Permeable cells were prepared essentially as described by Lustig et al. (2007) and Ullu and Tschudi (1990). The only deviation from the published protocol is that the transcription buffer (TB) used contained $150 \mathrm{mM}$ sucrose, $20 \mathrm{mM}$ potassium, L-glutamate (Sigma), $10 \mathrm{mM}$ HEPES KOH (pH 7.9), $2.5 \mathrm{mM} \mathrm{MgCl}_{2}, 1 \mathrm{mM}$ dithiotheritol, and $10 \mu \mathrm{g} / \mathrm{mL}$ leupeptin. For slot blot analysis of the RNA synthesized in permeable cells, PCR products, or plasmids DNA were blotted on the membrane using a SF Microfiltration apparatus. Hybridization was carried out at $55^{\circ} \mathrm{C}$ in $60 \%$ (v/v) formamide, $2 \times$ SSC, $100 \mu \mathrm{g} / \mathrm{mL}$ salmon sperm DNA, $0.1 \%$ Sarcosyl, with the entire RNA fraction extracted from permeable cells. After hybridization, membranes were washed twice in $2 \times$ SSC, $0.1 \%$ SDS for $30 \mathrm{~min}$ at $65^{\circ} \mathrm{C}$.

\section{Microarray analysis}

Total RNA was isolated from uninduced cells and from PTB1 silenced cells and PTB2 silenced cells after $3 \mathrm{~d}$ of induction. RNA quality was determined using the Eukaryote Total RNA Nano 6000 assay kit (Agilent Technologies) on the Agilent Technologies 2100 Bioanalyzer. To generate the fluorescently labeled cRNA, total RNA was labeled using the Ambion Amino Allyl MessageAmp II aRNA kit (Ambion). A classical balanced block design with dye swap was used for comparing RNA extracted from PTB1 or PTB2 silenced cells and RNA extracted from uninduced cells. Arrays were blocked with $1 \%$ BSA, $0.1 \%$ SDS, $5 \times$ SSC at $42^{\circ} \mathrm{C}$ for $1 \mathrm{~h}$, rinsed with double-distilled water, and air-dried. Next, $1.5 \mu \mathrm{g}$ of cyanine 3-labeled and $1.5 \mu \mathrm{g}$ of cyanine 5-labeled aRNA were fragmented and hybridized to the T. brucei DNA microarrays obtained through NIAID's Pathogen Functional Genomics Resource Center, managed and funded by the Division of Microbiology and Infectious Diseases, NIAID, NIH, DHHS, and operated by the J. Craig Venter Institute using the Gene Expression hybridization kit (Agilent Technologies) for $16 \mathrm{~h}$ at $60^{\circ} \mathrm{C}$ in a hybridization oven. After hybridization, each array was subjected to three washes: first wash with $2 \times$ SSC, $0.1 \%$ SDS for $1 \mathrm{~min}$ at $55^{\circ} \mathrm{C}$, then $0.1 \times$ SSC, $0.1 \%$ SDS for $1 \mathrm{~min}$, and finally with $0.1 \times$ SSC for $1 \mathrm{~min}$, at room temperature. Arrays were scanned using the dual laser scanner (Agilent G2505B Microarray scanner). The data were then extracted from images by using Spotreader software (Niles Scientific). Flawed features identified by visual 
inspection of the array images were flagged, and the data from these features were removed prior to further analysis.

\section{Microarray data analysis}

The data from all arrays were analyzed using GeneSpring GX software (Agilent Technologies). Array normalization was performed using the intensity dependent Lowess normalization method (Yang et al. 2002). Analysis was performed on the log expression ratios that were produced during the normalization step. Data from three biological replicates were used to perform a $T$ test. The normalized data were analyzed to identify genes whose expression appeared to be significantly $(P$ value $<0.05)$, up- or down-regulated by an arbitrary cutoff of at least 1.5 -fold. Pearson correlation was used as similarity measure, and a heat map was constructed.

\section{RNase protection assay}

The anti-sense RNA probe was transcribed in vitro by T7 polymerase (Ambion Megascript T7) using a PCR product encoding for the gene and carrying the T7 promoter. Total RNA $(30 \mu \mathrm{g})$ was mixed with $10^{5} \mathrm{cpm}$ of gel-purified RNA probe and concentrated by ethanol precipitation. RNase protection was performed essentially as described (Ben Shlomo et al. 1997). The protected fragments were precipitated with ethanol in the presence of $20 \mu \mathrm{g}$ of glycogen and analyzed on a $6 \%$ polyacrylamide, $7 \mathrm{M}$ urea denaturing gel.

\section{Preparation of PTB1 and PTB2 recombinant proteins and preparation of antibodies}

The T. brucei PTB1 and PTB2 genes were amplified by PCR using primers listed in Supplemental Table S-1. The amplified fragments were cloned into the pET28a vector (Novagen) and expressed in Escherichia coli BL21 cells. The his-tagged proteins were purified by incubation with cobalt-based beads (BD Biosciences). The proteins were eluted with $150 \mathrm{mM}$ imidazole, and the buffer of the peak fractions was exchanged to $50 \mathrm{mM}$ Tris ( $\mathrm{pH} 8), 150 \mathrm{mM}$ $\mathrm{NaCl}, 1 \mathrm{mM}$ DTT using a PD-10 column (Amersham Biosciences). The fractions were snap-frozen in liquid nitrogen. To raise antibodies against PTB1 and PTB2, $400 \mu \mathrm{g}$ of the protein was emulsified with equal volume of complete adjuvant (Difco). The emulsions were injected subcutaneously to female New Zealand white rabbits. The first injection was followed by additional two injections of $200 \mu \mathrm{g}$ protein emulsified with an equal volume of incomplete adjuvant (Difco) at 2-wk intervals. Serum was collected and examined for reactivity by immunofluorescence and Western analysis.

\section{RNA cross-linking and immunoprecipitation}

T. brucei cells $\left(5 \times 10^{9}\right)$ were washed with PBS and then subjected to UV irradiation at $254 \mathrm{~nm}$ at intensity of $10 \mathrm{~mW} / \mathrm{cm}^{2}$ for $5 \mathrm{~min}$. Cells were washed twice with washing buffer $(20 \mathrm{mM}$ Tris- $\mathrm{HCl}$ at $\mathrm{pH} 7.4,100 \mathrm{mM} \mathrm{NaCl}, 3 \mathrm{mM} \mathrm{MgCl} 2$ ) and resuspended in $1 \times \mathrm{TB}$ buffer (specified above). Non-iodnet- 40 was added to a final concentration of $0.1 \%$, and cells were incubated for $5 \mathrm{~min}$ on ice. The cells were broken with a dounce homogenizer using 20 strokes. $\mathrm{KCl}$ was added to $0.3 \mathrm{M}$, and extraction was performed for $30 \mathrm{~min}$. The extract was cleared by centrifugation, and the salt concentration was adjusted to $0.15 \mathrm{M} \mathrm{KCl}$. For immunoprecipitation, Sepharose-Protein A conjugated beads (GE Healthcare Bio-Sciences) were used. The beads were incubated with antibodies in binding buffer $(150 \mathrm{mM} \mathrm{KCl}, 10 \mathrm{mM}$ HEPES $\mathrm{KOH}$ at $\mathrm{pH} 7.9,20 \mathrm{mM}$ potassium L-glutamate, $10 \mathrm{mM} \mathrm{MgCl}_{2}, 1 \mathrm{mM}$ dithiotheritol, $10 \mu \mathrm{g} / \mathrm{mL}$ leupeptin). The immunoprecipitated RNA was subjected to digestion $(0.4 \mathrm{mg} / \mathrm{mL}$ Proteinase- $\mathrm{K}$ in $1 \%$ SDS), and RNA was extracted with TRI reagent (Sigma). cDNA was prepared with random primers with an RT synthesis kit (Promega) and used for PCR. For control, immunoprecipitation was performed with preimmune rabbit serum.

\section{Coimmunoprecipitation}

Cells $(500 \mathrm{~mL}, \sim 107-183$ cells $/ \mathrm{mL}$ ) were harvested and washed with PBS. Extracts were prepared essentially as previously described (Lustig et al. 2005), except that extraction was at 50 $\mathrm{mM} \mathrm{KCl}$. For immunoprecipitation, Sepharose-Protein A conjugated beads (GE Healthcare Bio-Sciences) were used. The beads were coated with antibodies overnight in Buffer A 50 (Buffer A with $50 \mathrm{mM} \mathrm{KCl}$ ) and were then used to precipitate specific proteins from the extract. The proteins bound to the beads were separated on a $10 \%$ SDS-PAGE gel, blotted, and reacted with antiPTB1 and anti-PTB2.

\section{Microscopy}

Immunofluorescence was performed as previously described (Lustig et al. 2005); PTB2 anti-serum was diluted 1:100, and nuclei were stained with 40-6 diamidino-2-phenylindole (DAPI) for $5 \mathrm{~min}$. For cells expressing the PTB1-GFP construct, fluorescence was observed after fixation with $2 \%$ formaldehyde and nuclear staining. Cells were visualized using a Zeiss LSM 510 META inverted microscope.

\section{Size fractionation-column chromatography}

Cells $\left(5 \times 10^{9}\right)$ were harvested and washed, and extracts were produced using extraction buffer A (Michaeli et al. 1990). The cells were broken using a dounce homogenizer in the presence of $0.1 \% \mathrm{NP}-40$. $\mathrm{KCl}$ was added to $50 \mathrm{mM}$, and the extract was cleared using a $0.2 \mu \mathrm{m}$ filter. Fractionation was performed on an FPLC Superdex S-200 column, as described (Tkacz et al. 2007), and alternate fractions (12-26) were analyzed by Western analysis.

\section{Construction of the minigene carrying AATP11 trans-splicing signals}

The regulatory elements present in pNS21b carrying a luciferase reporter gene were used and are described by Siegel et al. (2005). The regulatory elements upstream of the luciferase gene were replaced by the $\beta$-tubulin intergenic region and cloned between $\mathrm{BglII}$ and XbaI sites to generate the plasmid pNS21c. To fuse the AATP11 trans-splicing regulatory sequence to the luciferase reporter in pNS21c, a PstI site was inserted by site directed mutagenesis $3 \mathrm{nt}$ upstream of the ATG of the luciferase in pNS21c. The AATP11 5' regulatory elements $(324 \mathrm{bp})$ were amplified using primers specified in Supplemental Table S-1. The PstI and BglII sites of pNS21b were replaced by the sequence from the AATP11 gene. A mutation to change the PPT site was introduced by site 
directed mutagenesis by PCR, using primers carrying the mutation, and $5^{\prime}$ and $3^{\prime}$ primers specified in Supplemental Table S-1.

\section{In vitro cross-linking of PTB to RNA substrates}

Pre-mRNA of AATP11 was produced by in vitro transcription with T7 RNA polymerase (Promega) using a PCR template carrying the T7 promoter from primers listed in Supplemental Table S-1. Labeled SL RNA was produced from wild-type using the permeable cell system, as described above (Ullu and Tschudi 1990). Whole cell extracts were prepared as previously described (Gunzl et al. 1995). Gel purified RNA $(5000 \mathrm{cpm})$ was incubated for $30 \mathrm{~min}$ on ice in the presence of $(10 \mathrm{mM}$ HEPES at $\mathrm{pH} 7.7$, $5 \mathrm{mM} \mathrm{MgCl}_{2}, 1 \mathrm{mM}$ EDTA, $100 \mathrm{mM} \mathrm{NaCl}$ ) and $30 \%$ cell extract or $100 \mathrm{ng}$ recombinant PTB1 protein. The reaction was then UV cross-linked at $254 \mathrm{~nm}\left(120 \mathrm{~mJ} / \mathrm{cm}^{2}\right)$ for $15 \mathrm{~min}$ using a Bio-Link cross-linker (Vilber Lourant). Samples were then treated with 10 $\mu \mathrm{g}$ RNaseA for $30 \mathrm{~min}$ at $37^{\circ} \mathrm{C}$. Proteins were analyzed on $10 \%$ SDS-polyacrylamide gel. For competition experiments with unlabeled RNA, wild-type and mutant AATP11 were in vitro transcribed using the T7 MegaScript kit (Ambion).

\section{SUPPLEMENTAL MATERIAL}

Supplemental material can be found at http://www.rnajournal.org.

\section{ACKNOWLEDGMENTS}

This study was supported by a United States-Israel Binational Science Foundation grant, by the Deutsche Forcshungsgemeinschaft (DFG), and by an International Research Scholar grant from the Howard Hughes Medical Institute to S.M. S.M. holds the David and Inez Myers Chair in RNA silencing of diseases. We thank T. Nicolai Siegal and George Cross (Rockefeller University) for providing us the vector, pNS21.

Received June 19, 2008; accepted November 17, 2008.

\section{REFERENCES}

Agabian, N. 1990. Trans splicing of nuclear pre-mRNAs. Cell 61: 1157-1160.

Altschul, S.F., Madden, T.L., Schaffer, A.A., Zhang, J., Zhang, Z., Miller, W., and Lipman, D.J. 1997. Gapped BLAST and PSIBLAST: A new generation of protein database search programs. Nucleic Acids Res. 25: 3389-3402.

Amir-Ahmady, B., Boutz, P.L., Markovtsov, V., Phillips, M.L., and Black, D.L. 2005. Exon repression by polypyrimidine tract binding protein. RNA 11: 699-716.

Ashiya, M. and Grabowski, P.J. 1997. A neuron-specific splicing switch mediated by an array of pre-mRNA repressor sites: Evidence of a regulatory role for the polypyrimidine tract binding protein and a brain-specific PTB counterpart. RNA 3: 996-1015.

Ben Shlomo, H., Levitan, A., Beja, O., and Michaeli, S. 1997. The trypanosomatid Leptomonas collosoma 7SL RNA gene. Analysis of elements controlling its expression. Nucleic Acids Res. 25: 4977-4984.

Benz, C., Nilsson, D., Andersson, B., Clayton, C., and Guilbride, D.L. 2005. Messenger RNA processing sites in Trypanosoma brucei. Mol. Biochem. Parasitol. 143: 125-134.

Bushell, M., Stoneley, M., Kong, Y.W., Hamilton, T.L., Spriggs, K.A., Dobbyn, H.C., Qin, X., Sarnow, P., and Willis, A.E. 2006. Polypyrimidine tract binding protein regulates IRES-mediated gene expression during apoptosis. Mol. Cell 23: 401-412.
Carstens, R.P., Wagner, E.J., and Garcia-Blanco, M.A. 2000. An intronic splicing silencer causes skipping of the IIIb exon of fibroblast growth factor receptor 2 through involvement of polypyrimidine tract binding protein. Mol. Cell. Biol. 20: 73887400.

Chan, R.C. and Black, D.L. 1997. The polypyrimidine tract binding protein binds upstream of neural cell-specific c-src exon N1 to repress the splicing of the intron downstream. Mol. Cell. Biol. 17: $4667-4676$.

Chou, M.Y., Underwood, J.G., Nikolic, J., Luu, M.H., and Black, D.L. 2000. Multisite RNA binding and release of polypyrimidine tract binding protein during the regulation of c-src neural-specific splicing. Mol. Cell 5: 949-957.

Clayton, C.E. 2002. Life without transcriptional control? From fly to man and back again. EMBO J. 21: 1881-1888.

Clayton, C. and Shapira, M. 2007. Post-transcriptional regulation of gene expression in trypanosomes and leishmanias. Mol. Biochem. Parasitol. 156: 93-101.

Colasante, C., Robles, A., Li, C.H., Schwede, A., Benz, C., Voncken, F., Guilbride, D.L., and Clayton, C. 2007. Regulated expression of glycosomal phosphoglycerate kinase in Trypanosoma brucei. Mol. Biochem. Parasitol. 151: 193-204.

Cote, C.A., Gautreau, D., Denegre, J.M., Kress, T.L., Terry, N.A., and Mowry, K.L. 1999. A Xenopus protein related to hnRNP I has a role in cytoplasmic RNA localization. Mol. Cell 4: 431-437.

Cote, J., Dupuis, S., and Wu, J.Y. 2001. Polypyrimidine track-binding protein binding downstream of caspase-2 alternative exon 9 represses its inclusion. J. Biol. Chem. 276: 8535-8543.

D'Orso, I. and Frasch, A.C. 2002. TcUBP-1, an mRNA destabilizing factor from trypanosomes, homodimerizes and interacts with novel AU-rich element- and poly(A)-binding proteins forming a ribonucleoprotein complex. J. Biol. Chem. 277: 50520-50528.

De Gaudenzi, J., Frasch, A.C., and Clayton, C. 2005. RNA-binding domain proteins in Kinetoplastids: A comparative analysis. Eukaryot. Cell 4: 2106-2114.

Gooding, C., Roberts, G.C., and Smith, C.W. 1998. Role of an inhibitory pyrimidine element and polypyrimidine tract binding protein in repression of a regulated $\alpha$-tropomyosin exon. RNA 4: 85-100.

Gunzl, A., Tschudi, C., Nakaar, V., and Ullu, E. 1995. Accurate transcription of the Trypanosoma brucei U2 small nuclear RNA gene in a homologous extract. J. Biol. Chem. 270: 17287-17291.

Hug, M., Hotz, H.R., Hartmann, C., and Clayton, C. 1994. Hierarchies of RNA-processing signals in a trypanosome surface antigen mRNA precursor. Mol. Cell. Biol. 14: 7428-7435.

Ivens, A.C., Peacock, C.S., Worthey, E.A., Murphy, L., Aggarwal, G., Berriman, M., Sisk, E., Rajandream, M.A., Adlem, E., Aert, R., et al. 2005. The genome of the kinetoplastid parasite, Leishmania major. Science 309: 436-442.

Izquierdo, J.M., Majos, N., Bonnal, S., Martinez, C., Castelo, R., Guigo, R., Bilbao, D., and Valcarcel, J. 2005. Regulation of Fas alternative splicing by antagonistic effects of TIA-1 and PTB on exon definition. Mol. Cell 19: 475-484.

Jager, A.V., De Gaudenzi, J.G., Cassola, A., D’Orso, I., and Frasch, A.C. 2007. mRNA maturation by two-step trans-splicing/ polyadenylation processing in trypanosomes. Proc. Natl. Acad. Sci. 104: 2035-2042.

Kamath, R.V., Leary, D.J., and Huang, S. 2001. Nucleocytoplasmic shuttling of polypyrimidine tract-binding protein is uncoupled from RNA export. Mol. Biol. Cell 12: 3808-3820.

Kosinski, P.A., Laughlin, J., Singh, K., and Covey, L.R. 2003. A complex containing polypyrimidine tract-binding protein is involved in regulating the stability of CD40 ligand (CD154) mRNA. J. Immunol. 170: 979-988.

LeBowitz, J.H., Smith, H.Q., Rusche, L., and Beverley, S.M. 1993. Coupling of poly(A) site selection and trans-splicing in Leishmania. Genes \& Dev. 7: 996-1007.

Le Guiner, C., Plet, A., Galiana, D., Gesnel, M.C., Gatto-Konczak, F., and Breathnach, R. 2001. Polypyrimidine tract-binding protein 
represses splicing of a fibroblast growth factor receptor-2 gene alternative exon through exon sequences. J. Biol. Chem. 276: 43677-43687.

Le Sommer, C., Lesimple, M., Mereau, A., Menoret, S., Allo, M.R., and Hardy, S. 2005. PTB regulates the processing of a 3 '-terminal exon by repressing both splicing and polyadenylation. Mol. Cell. Biol. 25: 9595-9607.

Liang, X.H., Haritan, A., Uliel, S., and Michaeli, S. 2003. trans and cis splicing in Trypanosomatids: Mechanism, factors, and regulation. Eukaryot. Cell 2: 830-840.

Liang, X.H., Liu, Q., Liu, L., Tschudi, C., and Michaeli, S. 2006. Analysis of spliceosomal complexes in Trypanosoma brucei and silencing of two splicing factors Prp31 and Prp43. Mol. Biochem. Parasitol. 145: 29-39.

Lin, C.H. and Patton, J.G. 1995. Regulation of alternative $3^{\prime}$ splice site selection by constitutive splicing factors. RNA 1: 234-245.

Liu, Q., Liang, X.H., Uliel, S., Belahcen, M., Unger, R., and Michaeli, S. 2004. Identification and functional characterization of Lsm proteins in Tryapnosoma brucei. J. Biol. Chem. 279: 1821018219.

Lustig, Y., Goldshmidt, H., Uliel, S., and Michaeli, S. 2005. The Trypanosoma brucei signal recognition particle lacks the Aludomain-binding proteins: Purification and functional analysis of its binding proteins by RNAi. J. Cell Sci. 118: 4551-4562.

Lustig, Y., Sheiner, L., Vagima, Y., Goldshmidt, H., Das, A., Bellofatto, V., and Michaeli, S. 2007. Spliced-leader RNA silencing: A novel stress-induced mechanism in Trypanosoma brucei. EMBO Rep. 8: 408-413.

Mair, G., Shi, H., Li, H., Djikeng, A., Aviles, H.O., Bishop, J.R., Falcone, F.H., Gavrilescu, C., Montgomery, J.L., Santori, M.I., et al. 2000. A new twist in trypanosome RNA metabolism: cis-splicing of pre-mRNA. RNA 6: 163-169.

Mandelboim, M., Barth, S., Biton, M., Liang, X.H., and Michaeli, S. 2003. Silencing of Sm proteins in Trypanosoma brucei by RNA interference captured a novel cytoplasmic intermediate in spliced leader RNA biogenesis. J. Biol. Chem. 278: 51469-51478.

Maris, C., Dominguez, C., and Allain, F.H. 2005. The RNA recognition motif, a plastic RNA-binding platform to regulate posttranscriptional gene expression. FEBS J. 272: 2118-2131.

Martinez-Contreras, R., Cloutier, P., Shkreta, L., Fisette, J.F., Revil, T., and Chabot, B. 2007. hnRNP proteins and splicing control. Adv. Exp. Med. Biol. 623: 123-147.

Matthews, K.R., Tschudi, C., and Ullu, E. 1994. A common pyrimidine-rich motif governs trans-splicing and polyadenylation of tubulin polycistronic pre-mRNA in trypanosomes. Genes \& Dev. 8: 491-501.

Michaeli, S., Roberts, T.G., Watkins, K.P., and Agabian, N. 1990. Isolation of distinct small ribonucleoprotein particles containing the spliced leader and U2 RNAs of Trypanosoma brucei. J. Biol. Chem. 265: 10582-10588.

Mulligan, G.J., Guo, W., Wormsley, S., and Helfman, D.M. 1992. Polypyrimidine tract binding protein interacts with sequences involved in alternative splicing of $\beta$-tropomyosin pre-mRNA. J. Biol. Chem. 267: 25480-25487.

Nakaar, V., Dare, A.O., Hong, D., Ullu, E., and Tschudi, C. 1994. Upstream tRNA genes are essential for expression of small nuclear and cytoplasmic RNA genes in trypanosomes. Mol. Cell. Biol. 14: 6736-6742.

Oberstrass, F.C., Auweter, S.D., Erat, M., Hargous, Y., Henning, A., Wenter, P., Reymond, L., Amir-Ahmady, B., Pitsch, S., Black, D.L., et al. 2005. Structure of PTB bound to RNA: Specific binding and implications for splicing regulation. Science 309: 2054-2057.

Perez, I., Lin, C.H., McAfee, J.G., and Patton, J.G. 1997. Mutation of PTB binding sites causes misregulation of alternative $3^{\prime}$ splice site selection in vivo. RNA 3: 764-778.

Robles, A. and Clayton, C. 2008. Regulation of an amino acid transporter mRNA in Trypanosoma brucei. Mol. Biochem. Parasitol. 157: $102-106$.
Schnaufer, A., Ernst, N.L., Palazzo, S.S., O’Rear, J., Salavati, R., and Stuart, K. 2003. Separate insertion and deletion subcomplexes of the Trypanosoma brucei RNA editing complex. Mol. Cell 12: 307-319.

Sharma, S., Kohlstaedt, L.A., Damianov, A., Rio, D.C., and Black, D.L. 2008. Polypyrimidine tract binding protein controls the transition from exon definition to an intron defined spliceosome. Nat. Struct. Mol. Biol. 15: 183-191.

Shen, H., Kan, J.L., Ghigna, C., Biamonti, G., and Green, M.R. 2004. A single polypyrimidine tract binding protein (PTB) binding site mediates splicing inhibition at mouse IgM exons M1 and M2. RNA 10: 787-794.

Siegel, T.N., Tan, K.S., and Cross, G.A. 2005. Systematic study of sequence motifs for RNA trans splicing in Trypanosoma brucei. Mol. Cell. Biol. 25: 9586-9594.

Singh, R., Valcarcel, J., and Green, M.R. 1995. Distinct binding specificities and functions of higher eukaryotic polypyrimidine tract-binding proteins. Science 268: 1173-1176.

Smith, C.W. and Valcarcel, J. 2000. Alternative pre-mRNA splicing: The logic of combinatorial control. Trends Biochem. Sci. 25: 381-388.

Soderberg, M., Raffalli-Mathieu, F., and Lang, M.A. 2002. Inflammation modulates the interaction of heterogeneous nuclear ribonucleoprotein (hnRNP) I/polypyrimidine tract binding protein and hnRNP L with the $3^{\prime}$ untranslated region of the murine inducible nitric-oxide synthase mRNA. Mol. Pharmacol. 62: 423-431.

Sogin, M.L., Elwood, H.J., and Gunderson, J.H. 1986. Evolutionary diversity of eukaryotic small-subunit rRNA genes. Proc. Natl. Acad. Sci. 83: 1383-1387.

Spellman, R. and Smith, C.W.J. 2006. Novel modes of splicing repression by PTB. Trends Biochem. Sci. 31: 73-76.

Stamm, S. 2008. Regulation of alternative splicing by reversible protein phosphorylation. J. Biol. Chem. 283: 1223-1227.

Tillmar, L. and Welsh, N. 2004. Glucose-induced binding of the polypyrimidine tract-binding protein (PTB) to the 3 - -untranslated region of the insulin mRNA (ins-PRS) is inhibited by rapamycin. Mol. Cell. Biochem. 260: 85-90.

Tkacz, I.D., Lustig, Y., Stern, M.Z., Biton, M., Salmon-Divon, M., Das, A., Bellofatto, V., and Michaeli, S. 2007. Identification of novel snRNA-specific Sm proteins that bind selectively to U2 and U4 snRNAs in Trypanosoma brucei. RNA 13: 30-43.

Tschudi, C. and Ullu, E. 1990. Destruction of U2, U4, or U6 small nuclear RNA blocks trans splicing in trypanosome cells. Cell 61: 459-466.

Ullu, E. and Tschudi, C. 1990. Permeable trypanosome cells as a model system for transcription and trans-splicing. Nucleic Acids Res. 18: 3319-3326.

Vazquez, M.P., Mualem, D., Bercovich, N., Stern, M.Z., Nyambega, B., Barda, O., Masiga, D., Gupta, S.K., Michaeli, S., and Levin, M.J. 2009. Functional characterization and proteinprotein interactions of trypanosome splicing factors U2AF35, U2AF65 and SF1. Mol. Biochem. Parasitol. (in press). doi: 10.1016/ j.molbiopara.2008.12.009.

Wagner, E.J. and Garcia-Blanco, M.A. 2001. Polypyrimidine tract binding protein antagonizes exon definition. Mol. Cell. Biol. 21: 3281-3288.

Wang, Z., Morris, J.C., Drew, M.E., and Englund, P.T. 2000. Inhibition of Trypanosoma brucei gene expression by RNA interference using an integratable vector with opposing T7 promoters. J. Biol. Chem. 275: 40174-40179.

Xu, Y., Liu, L., Lopez-Estrano, C., and Michaeli, S. 2001. Expression studies on clustered trypanosomatid box C/D small nucleolar RNAs. J. Biol. Chem. 276: 14289-14298.

Yang, Y.H., Dudoit, S., Luu, P., Lin, D.M., Peng, V., Ngai, J., and Speed, T.P. 2002. Normalization for cDNA microarray data: A robust composite method addressing single and multiple slide systematic variation. Nucleic Acids Res. 30: e15.

Zamore, P.D., Patton, J.G., and Green, M.R. 1992. Cloning and domain structure of the mammalian splicing factor U2AF. Nature 355: 609-614. 

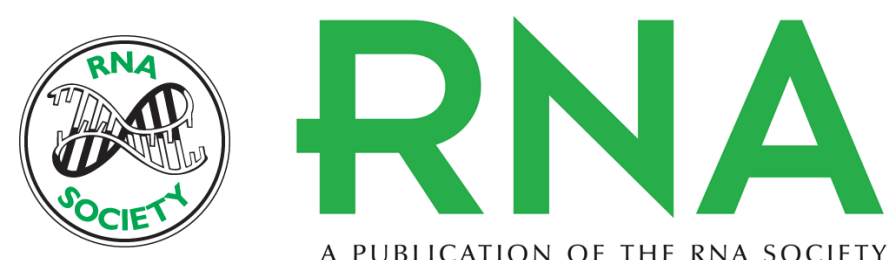

A PUBLICATION OF THE RNA SOCIETY

\section{Multiple roles for polypyrimidine tract binding (PTB) proteins in trypanosome RNA metabolism}

Michael Zeev Stern, Sachin Kumar Gupta, Mali Salmon-Divon, et al.

RNA 2009 15: 648-665 originally published online February 13, 2009

Access the most recent version at doi:10.1261/rna.1230209

\section{Supplemental http://rnajournal.cshlp.org/content/suppl/2009/02/17/rna.1230209.DC1 \\ Material}

References This article cites 64 articles, 40 of which can be accessed free at:

http://rnajournal.cshlp.org/content/15/4/648.full.html\#ref-list-1

\section{License}

Email Alerting Receive free email alerts when new articles cite this article - sign up in the box at the Service top right corner of the article or click here.

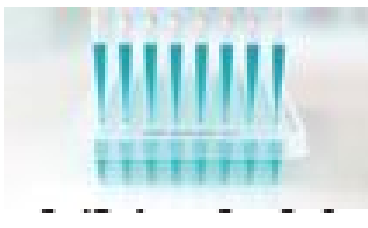

Providing Precise Solutions for your research.

To subscribe to RNA go to:

http://rnajournal.cshlp.org/subscriptions 